\title{
Back to the Wild: On a Quest for Donors Toward Salinity Tolerant Rice
}

\author{
Celymar A. Solis ${ }^{1,2+}$, Miing T. Yong ${ }^{1+}$, Ricky Vinarao ${ }^{3 \ddagger}, K_{\text {Shirod Jena }}^{3 \neq}$, Paul Holford ${ }^{1}$, \\ Lana Shabala ${ }^{2}$, Meixue Zhou ${ }^{2}$, Sergey Shabala ${ }^{2,4}$ and Zhong-Hua Chen ${ }^{1,5 *}$ \\ ${ }^{1}$ School of Science, Western Sydney University, Penrith, NSW, Australia, ${ }^{2}$ Tasmanian Institute of Agriculture, University \\ of Tasmania, Hobart, TAS, Australia, ${ }^{3}$ International Rice Research Institute, Metro Manila, Philippines, ${ }^{4}$ International \\ Research Centre for Environmental Membrane Biology, Foshan University, Foshan, China, ${ }^{5}$ Hawkesbury Institute \\ for the Environment, Western Sydney University, Penrith, NSW, Australia
}

OPEN ACCESS

Edited by:

Camilla Hill,

Murdoch University, Australia

Reviewed by:

Lubin Tan,

China Agricultural University, China

Wricha Tyagi,

Central Agricultural University, India

*Correspondence:

Zhong-Hua Chen

z.Chen@westernsydney.edu.au;

z.chen@uws.edu.au

†These authors have contributed equally to this work

${ }^{\ddagger}$ Present address:

Ricky Vinarao,

School of Agriculture and Food

Science, University of Queensland,

St Lucia, QLD, Australia

Kshirod Jena,

School of Biotechnology, Kalinga Institute of Industrial Technology,

Bhubaneswar, India

Specialty section:

This article was submitted to Plant Abiotic Stress,

a section of the journal

Frontiers in Plant Science

Received: 07 January 2020

Accepted: 05 March 2020

Published: 20 March 2020

Citation:

Solis $C A$, Yong $M T$, Vinarao $R$,

Jena $K$, Holford P, Shabala L, Zhou M, Shabala $S$ and Chen Z-H (2020) Back to the Wild: On a Quest

for Donors Toward Salinity Tolerant

Rice. Front. Plant Sci. 11:323.

doi: 10.3389/fpls.2020.00323
Salinity stress affects global food producing areas by limiting both crop growth and yield. Attempts to develop salinity-tolerant rice varieties have had limited success due to the complexity of the salinity tolerance trait, high variation in the stress response and a lack of available donors for candidate genes for cultivated rice. As a result, finding suitable donors of genes and traits for salinity tolerance has become a major bottleneck in breeding for salinity tolerant crops. Twenty-two wild Oryza relatives have been recognized as important genetic resources for quantitatively inherited traits such as resistance and/or tolerance to abiotic and biotic stresses. In this review, we discuss the challenges and opportunities of such an approach by critically analyzing evolutionary, ecological, genetic, and physiological aspects of Oryza species. We argue that the strategy of rice breeding for better $\mathrm{Na}^{+}$exclusion employed for the last few decades has reached a plateau and cannot deliver any further improvement in salinity tolerance in this species. This calls for a paradigm shift in rice breeding and more efforts toward targeting mechanisms of the tissue tolerance and a better utilization of the potential of wild rice where such traits are already present. We summarize the differences in salinity stress adaptation amongst cultivated and wild Oryza relatives and identify several key traits that should be targeted in future breeding programs. This includes: (1) efficient sequestration of $\mathrm{Na}^{+}$in mesophyll cell vacuoles, with a strong emphasis on control of tonoplast leak channels; (2) more efficient control of xylem ion loading; (3) efficient cytosolic $\mathrm{K}^{+}$ retention in both root and leaf mesophyll cells; and (4) incorporating $\mathrm{Na}^{+}$sequestration in trichrome. We conclude that while amongst all wild relatives, $O$. rufipogon is arguably a best source of germplasm at the moment, genes and traits from the wild relatives, O. coarctata, O. latifolia, and O. alta, should be targeted in future genetic programs to develop salt tolerant cultivated rice.

Keywords: wild rice, salinity stress, molecular breeding, rice domestication, 0 . coarctata, 0 . rufipogon

\section{INTRODUCTION}

Rice (Oryza sativa L.) is one of the most important staple crops in many countries. It is the main food source of over half of the world population accounting for about $50-80 \%$ of their daily calorie intake (International Rice Genome Sequencing Project, 2005; Food and Agriculture Organization, 2019). With an increasing world population, there is a need to increase rice production by $87 \%$ 
by 2050 (Kromdijk and Long, 2016). This is a challenging task, as the amount of arable land available to meet this demand for the increase in rice production is simply insufficient using current practices. Moreover, a large proportion of the global food production will have to deal with erratic environmental conditions and abiotic stresses due to climate change (Food and Agriculture Organization, 2019).

It is estimated that approximately 950 million hectares of arable land globally, including 250 million hectares of irrigated land, is affected by salinity (Yamaguchi and Blumwald, 2005; Shahbaz and Ashraf, 2013). Among the cereal crops, rice is the most sensitive to salinity, and high salt concentrations in soils are considered as one of the major abiotic stresses affecting rice production (Eynard et al., 2005). Rice is grown in over 100 countries in an area of more than 150 million hectares of land; however, a large proportion of these agricultural areas are salinized to some degree or are at risk of being salinized. This involves millions of hectares in South Asia and Southeast Asia that are climatically suited for rice production but are left uncultivated or have low yields due to saline soils (Smajgl et al., 2015). However, the demand for rice is rising due to increasing populations in countries where rice is the staple food and the growing global popularity of rice cuisines. Given the economic significance of rice, understanding the mechanisms of adaptation to salinity stress and, subsequently, developing salinity-tolerant genotypes can be a means of increasing rice production. Major efforts have been made to increase the salt tolerance of rice through conventional and molecular breeding, but the extent of increase in salt tolerance has been limited, especially under field conditions (Hoang et al., 2016).

Wild Oryza species are a prime reservoir of genetic diversity for the improvement of one the world's most important food crops. The genus is composed of two domesticated species, Oryza sativa and Oryza glaberrima, and 22 wild species that represent between 15 and 25 million years of evolutionary diversification (Vaughan, 1994). Wild rice relatives have been identified as potential sources of important agronomic traits. Modern breeding approaches to stress tolerance have been focused on the identification of the sources of genetic diversity in the primary gene pool and then introgressing favorable alleles into elite cultivars to combat the stresses (Gur and Zamir, 2004; Sharma et al., 2013). Introgression of favorable alleles into elite rice varieties has been successful for development of lines that are resistant to pests and diseases (Jena and Kim, 2010; Sarao et al., 2016) and higher yields (Swamy and Sarla, 2008; Bai et al., 2012), but to a less extent for tolerance to drought, cold and salinity (Koseki et al., 2010; Ndjiondjop et al., 2010; Yang et al., 2012).

In this review, we discuss the genus Oryza and its genetic complexity and the limitations in the potential use of these wild rice species, with a focus on breeding of salinity-tolerant rice. We elucidate the variability in response to salinity amongst Oryza species and propose some key genes from wild rice as targets for further research toward the identification of salt tolerance mechanisms in wild rice species for the improvement of cultivated rice.

\section{THE COMPLEX Oryza GENUS AND THE EVOLUTION AND DOMESTICATION OF MODERN CULTIVATED RICE}

The genus, Oryza, has a rich genetic diversity that comprises different landraces, modern and obsolete varieties, genetic stocks, and wild Oryza species (Zhang and Gao, 2017). Modern cultivated rice has evolved from its wild progenitors through a series of introgressive events, natural selection, domestication, and conventional and molecular breeding. Given these processes, just two of the 24 extant Oryza species have become agronomically productive: "Asian rice," Oryza sativa, that is high yielding and cultivated worldwide and "African rice," Oryza glaberrima, that is low yielding and grown in limited areas in West Africa (Vaughan, 1994; Linares, 2002; Vaughan et al., 2003). The domestication of these two cultivated rice species shows parallel evolution in which different human civilizations selected different wild species to target the same traits (Purugganan, 2014). These traits resulted in major alterations in rice plant structure and reproductive physiology. Rice breeders have selected for the characteristics of rice grains that make them more appealing as a food source, including grain size, shape, color, and fragrance (Kovach et al., 2007). Despite being widely studied, the domestication of these two cultivated species remains controversial (Wambugu et al., 2018). Modern genetic and genomic studies of cultivated and wild rice will provide useful information and vital insights into the evolution and domestication of rice (Kovach et al., 2007).

The 22 wild species have native distributions in tropical and subtropical regions of Africa, South-East Asia, Australasia, and Central and South America (Supplementary Table S1). These wild rice relatives are weedy grasses (Figure 1) that have inferior morpho-physiological characteristics, poor grain attributes, and low seed set compared to cultivated rice. These wild rice species also differ substantially in their growth habitat and morphological characteristics such as plant height, leaf shape and size, tiller numbers, flowering, panicle size, and branching (Vaughan et al., 2003). Fifteen of the 22 wild Oryza species have been assigned to six diploid genome types (AA, BB, CC, EE, FF, and GG) and the remaining seven species to three tetraploid species types (BBCC, CCDD, and HHJJ) (Figure 2). These types are determined based on cytogenetic analysis (Morinaga, 1964), genomic DNA hybridization (Aggarwal et al., 1997), rDNA spacers (Cordesse et al., 1992), transposons (Iwamoto et al., 1999; Kanazawa et al., 2000), and DNA sequence comparisons of two Adh genes (Ge et al., 1999). Although the genome of O. sativa (AA) has been fully determined, many aspects of the evolution of the Oryza genus and their phylogenetic relationships (Stein et al., 2018) remain to be clarified.

The genus Oryza can be grouped into four species "complexes": (1) the primary gene pool, the O. sativa complex; (2) the O. officinalis complex; (3) the O. ridleyi complex; and (4) the 


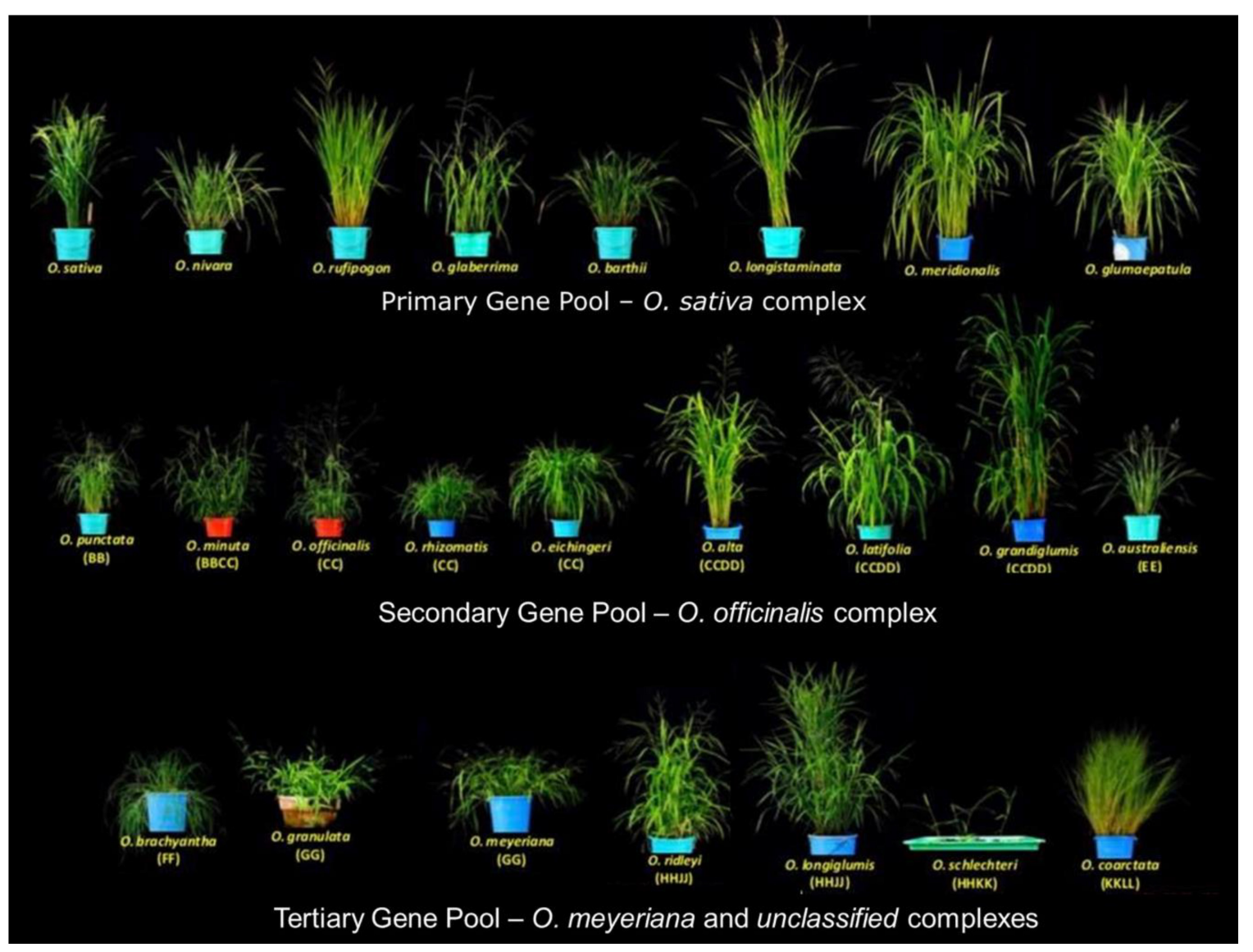

FIGURE 1 | Diversity of wild rice species. The 24 wild Oryza species are divided into a primary gene pool (Oryza sativa complex, AA genome), a secondary gene pool (Oryza officinalis complex, BB to EE genomes), and a tertiary gene pool (O. meyeriana complex and unclassified species, FF to KKLL genomes). Images are taken by the authors at the International Rice Research Institute (IRRI).

O. meyeriana complex (Supplementary Table S1). The O. sativa complex comprises eight diploid species with AA genomes that encompasses two cultivated (O. sativa and O. glaberrima) and six wild rice species (O. nivara, O. rufipogon, O. breviligulata, O. longistaminata, O. meridionalis, and O. glumaepatula). These species are commonly used by breeders due to their ease of crossing and gene transfer to cultivated rice cultivars (Brar and Khush, 2018). The most widely used ancestral wild rice, O. rufipogon, is found in regions of South Asia, Southeast Asia and Northern Australia, and has both annual and perennial types. Perennial O. rufipogon subtypes are found in deep swamps, while the annual subtypes are found in shallower, temporary swamps which are parched in the dry season (Morishima et al., 1984). O. rufipogon has been used for many decades for the breeding of disease- and insect-resistant rice (Song et al., 2005; Stein et al., 2018; Wing et al., 2018). O. nivara is an annual grass within the $O$. sativa complex that is distributed in India, Nepal, Cambodia, Laos, and Thailand. As with O. rufipogon, it has been used to breed high-yielding, virus-resistant rice cultivars (Varshney et al., 2009; Brar and Singh, 2011; Swamy et al., 2014). A few introgression lines have been developed using yield-associated QTLs from O. nivara (Ma et al., 2016).
Oryza longistaminata, a perennial plant that is widely distributed in Africa, is closely related to its annual relative, O. barthii (Akimoto et al., 1998). These two species are closely related to O. glaberrima, which mainly distributed in Western Africa in upland, rain-fed and deep-water fields (Linares, 2002; Wang et al., 2014). Oryza glaberrima can be easily distinguished from O. sativa due to its short, rounded ligule and no secondary panicle branching (Vaughan et al., 2003). Oryza glaberrima is tolerant to different biotic and abiotic stresses, but its yield is not high (Futakuchi et al., 2012).

The O. officinalis complex comprises six diploid species (O. punctata, O. minuta, O. officinalis, O. eichingeri, O. rhizomatis, O. australiensis) and six allotetraploid species (O. punctata, O. minuta, O. officinalis, O. latifolia, O. alta, and O. grandiglumis) (Brar and Khush, 2018). This complex is distributed in Asia, Africa, and Latin America. In Asia, the most common species are O. minuta and O. officinalis (Vaughan, 1989); O. punctata (BB, annual, BBCC perennial) and O. eichngeri (CC) are mainly found in Africa (Vaughan et al., 2003). The three allotetraploids, O. latifolia, O. alta, and O. grandiglumis (CCDD), are found in the Latin America. Oryza latifolia is widely distributed in Central and South America 


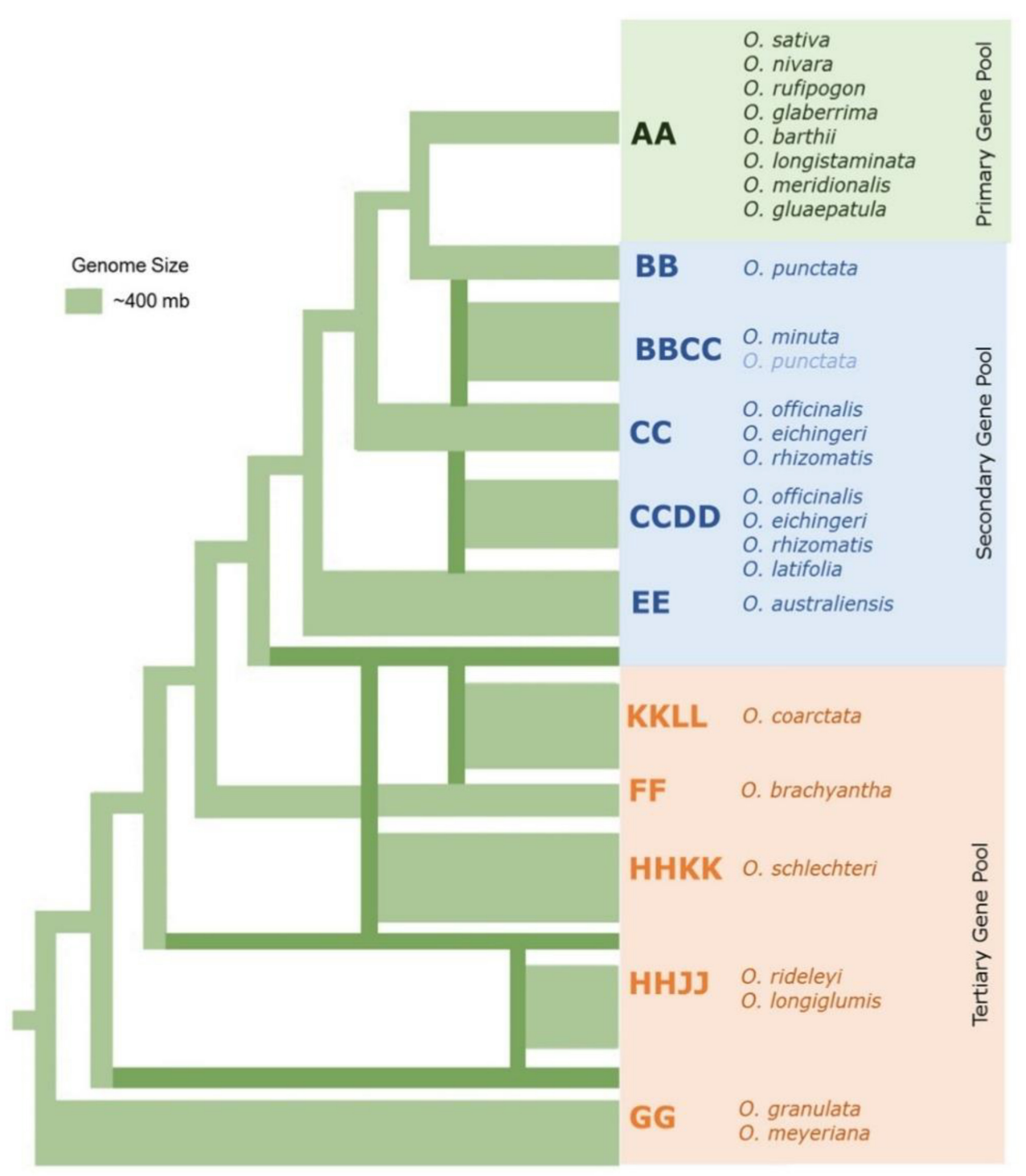

FIGURE 2 | The phylogenetic relationships among the major wild rice species. Neighbor joining tree in which the thickness of the lines connecting to each lineage represents approximate genome size modified from Ge et al. (1999); Lu et al. (2009), and Ammiraju et al. (2010).

and the Caribbean islands while O. alta and O. grandiglumis grows in the Amazon basin of South America (Bao and Ge, 2004). Oryza australiensis (EE) is commonly found in northern parts of Australia and survives as both rhizomes and seeds. This species has the largest genome in the genus, Oryza, due to a retrotransposon (Piegu et al., 2006).

The O. ridleyi complex comprises two tetraploid (HHJJ genomes) species, $O$. ridleyi and $O$. longiglumis, that are commonly found in Asia and have highly similar morphological and ecological characteristics. Rice breeders have used these species to breed cultivars resistant to bacterial blight and blast (Vaughan et al., 2003). The O. meyeriana complex is composed of two species, O. meyeriana and O. granulata, both with diploid GG genomes. Compared to species in the other complexes, these plants are small with unbranched panicles and small spikelets.
They thrive in shady or partial shady forest understory and cannot survive flooding (Vaughan et al., 2003). Two of the 24 species are yet to be classified among the complexes: O. schleteri (HHKK), which is distributed in regions of Indonesia and Papua New Guinea; and O. coarctata (KKLL), which is commonly found in coastal areas of South Asia (Vaughan et al., 2003).

\section{SEARCH FOR DONORS FOR SALT TOLERANT RICE}

There are numerous rice varieties widespread across the globe, with over 127,000 reported accessions of cultivated rice and wild relatives (Supplementary Table S1). Among the known accessions, there are thousands of hybrid rice cultivars that have 
characterized quantitative traits such as grain yield, flowering time and plant architecture. There are also classic elite cultivars, such as IR64, Teqing and IR68552-55-3-2, that are used as recurrent parental lines (Huang et al., 2016). However, only a small proportion of these natural accessions have been assessed for traits under saline conditions using different screening approaches and experimental designs (Platten et al., 2013; Kumar et al., 2015). It has been found that the salt tolerance of cultivars of O. glaberrima and O. sativa is related to low $\mathrm{Na}^{+}$and high $\mathrm{K}^{+}$ concentrations in roots and shoots (Reddy et al., 2014; Rahman et al., 2016; Sakina et al., 2016), and some of the most salttolerant cultivars are Pokkali, Nona Bokra, and FL478 (Zeng and Shannon, 2000; Platten et al., 2013). These salt-tolerant cultivars have been extensively used in breeding salinity-tolerant rice (Thomson et al., 2010; Platten et al., 2013; Reddy et al., 2014; Waziri et al., 2016). However, the degree of salt tolerance has often been low, and the developed plants possess tolerance like the donors but with poor agronomical traits. Most of these poor agronomical traits are linked with salinity tolerance, making it difficult to untangle them and produce tolerant lines while avoiding linkage drag of these poor agronomic traits from the donors (Gregorio et al., 2002). Also, the developed lines often survived only under glasshouse conditions and failed to show salinity tolerance in the field due to combined stresses (Reddy et al., 2014). Thus, it appears that the extent of genetic variability in salinity tolerance in cultivated rice is not large enough to enable any significant improvement in this trait and create varieties capable of handling the substantial amounts of salt that can be present in the rhizosphere.

Compared to cultivated rice, the wild rice species have greater genetic diversity. It is estimated that $10-20 \%$ of wild rice species diversity is represented in cultivated rice (Zhu et al., 2007; Stein et al., 2018). The large genetic diversity suggests that novel salinity tolerance mechanisms can be explored for the potential utilization of genes and traits contained in this diversity. Thus, an attractive breeding strategy could be to combine salinity-adaptive traits from wild rice through gene pyramiding in popular varieties and elite breeding lines (Gregorio et al., 2002).

\section{MECHANISMS OF ADAPTATION TO SALINITY STRESS IN RICE}

\section{Physiological Mechanisms of Rice Salt Tolerance}

Rice is the most salinity-sensitive species among the cereal crops, where $3 \mathrm{dSm}^{-1}$ of salinity is sufficient to cause significant yield reductions in most cultivated varieties (Eynard et al., 2005). The salt tolerance of rice varies at different growth stages. The crop is relatively tolerant during seed germination (Khan et al., 1997) and the early vegetative stage (shoot and root emerge until the first tiller grows) (Zeng and Shannon, 2000), but it is susceptible at the seedling stage (Lutts et al., 1996) and highly susceptible at the reproductive stage (Khatun and Flowers, 1995). The major morphological symptoms in salinity-sensitive rice varieties include stunted roots and shoots, leaf tip burning, low tiller numbers, reduced numbers of florets per panicle, low pollen viability, spikelet sterility, reduced panicle numbers, low grain weight, and low harvest index and yield (Zeng and Shannon, 2000; Singh et al., 2008).

Plants generally adapt to salinity stress by mechanisms related to ion exclusion and osmotic tolerance (Figure 3) (Munns and Tester, 2008; Reddy et al., 2017; Munns et al., 2020). Ion exclusion is traditionally considered to be related to minimizing the initial entry of salt into roots and/or its efficient retention in the roots thus preventing excess accumulation of $\mathrm{Na}^{+}$and $\mathrm{Cl}^{-}$ions in the leaves (Roy et al., 2014). As a result of selective breeding, salttolerant rice varieties accumulate less $\mathrm{Na}^{+}$in leaves and shoots than those of salt-sensitive cultivars (Golldack et al., 2003; Lee et al., 2003; Lin et al., 2004; Ren et al., 2005; Cotsaftis et al., 2012). Ion exclusion also includes the retrieval of $\mathrm{Na}^{+}$into xylem parenchymal cells and the efflux of ions back into the soil. Osmotic tolerance is related to a plant's ability to increase production of organic osmolytes and/or the use of inorganic salts for osmotic adjustment. This osmotic adjustment is critical to maintain leaf expansion and operate stomatal movements (Roy et al., 2014). A plant's reliance on inorganic ions for osmotic adjustment implies efficient vacuolar $\mathrm{Na}^{+}$compartmentation (Shabala et al., 2019) and represents an important component of the tissue tolerance mechanism, e.g., an ability to maintain optimal functioning in the presence of high $\mathrm{Na}^{+}$and $\mathrm{Cl}^{-}$in plant tissues. This requires compartmentalization of $\mathrm{Na}^{+}$and $\mathrm{Cl}^{-}$at the cellular and intracellular levels to avoid toxic concentrations within the cytoplasm (Chen et al., 2007b; Shabala et al., 2019), especially in leaf mesophyll cells. As a result of this sequestration, plants are capable of maintaining a high tissue $\mathrm{K}^{+} / \mathrm{Na}^{+}$ratio that is considered a key determinant of salinity stress tolerance (Maathuis and Amtmann, 1999; Anschütz et al., 2014; Shabala and Pottosin, 2014). In addition, plants use compatible solutes and produce enzymes catalyzing the detoxification of reactive oxygen species (ROS) (Bartels and Sunkar, 2005; Chen et al., 2007a) to deal with the oxidative component of the salt stress.

\section{Molecular Mechanisms for Rice Salt Tolerance}

Salinity tolerance is a complex, quantitative trait that is controlled by multiple factors, and many genes have been reported to enhance salt tolerance in rice. These genes fall in three categories: (1) genes for salt uptake, transport and signaling; (2) genes for osmoprotection; and (3) genes for maintaining energy balance for normal growth under salinity stress (Munns et al., 2020). Figure 3 shows some of the key genes involved in salt tolerance that are likely to be relevant for controlling $\mathrm{K}^{+}$or $\mathrm{Na}^{+}$uptake by roots and transport within the plant. $\mathrm{Na}^{+}$uptake in the roots from soil is mediated primarily by non-selective cation channels (NSCCs) that have similar permeability to $\mathrm{Na}^{+}$and $\mathrm{K}^{+}$(Demidchik et al., 2002) and through $\mathrm{K}^{+}$transporters (HKTs) that mediate $\mathrm{Na}^{+}$ and $\mathrm{K}^{+}$transport (Tester and Davenport, 2003; Plett and Møller, 2010; Hanin et al., 2016). The $\mathrm{Na}^{+}$absorbed by the root moves to the xylem via other transporters and channels and is delivered to the shoots (Munns and Tester, 2008). Regulating transport of $\mathrm{Na}^{+}$is crucial in salinity stress adaptation in rice. OsHKT1;5 


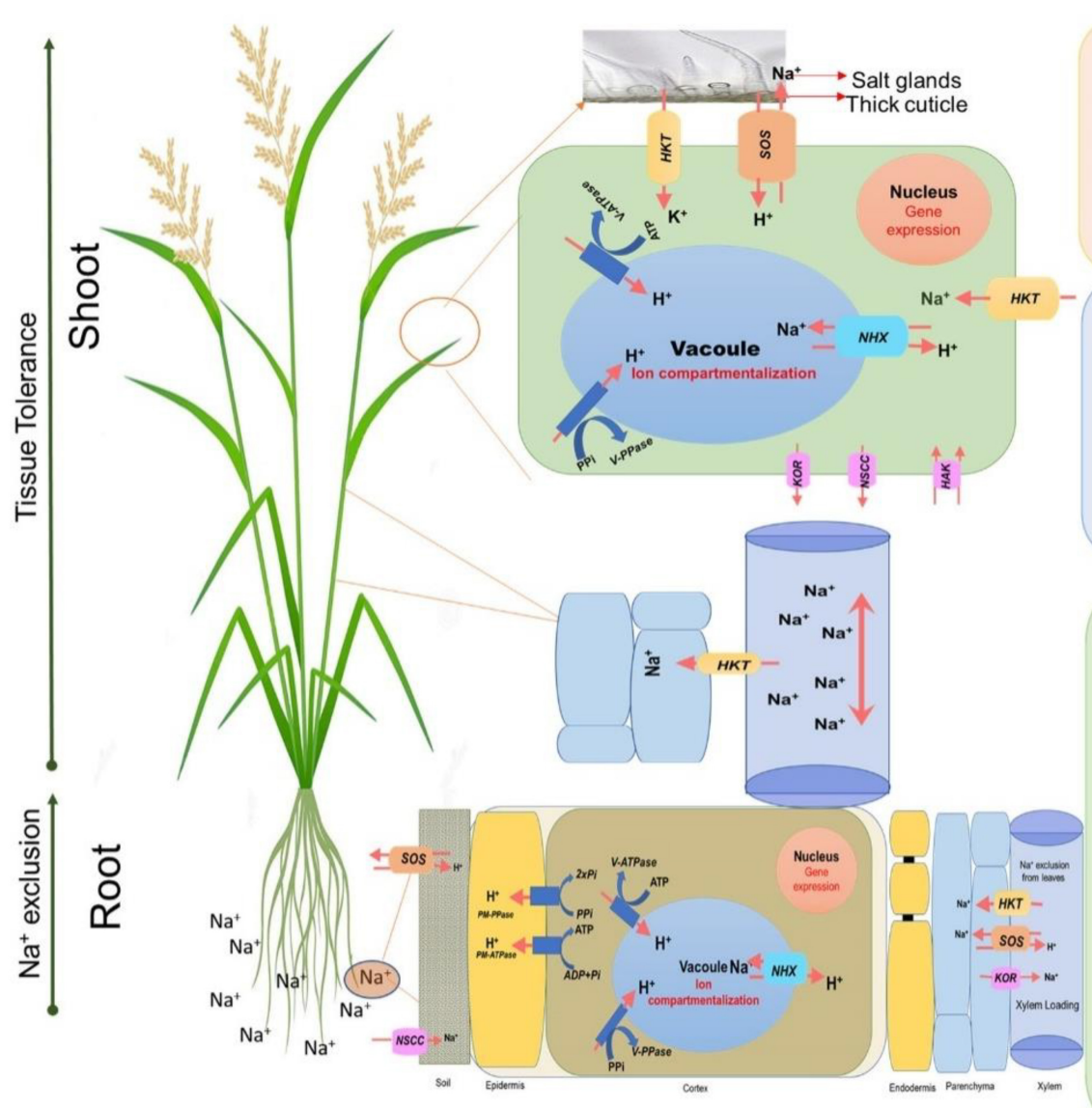

Key features find in wild rice

relatives:

- Salt excretion through salt

bladders/hairs

- Succulence

- Higher epicuticular wax content

- Higher stomatal density

- Altered flowering pattern

Cell level adaptation

- Osmotic adjustment

- $\mathrm{Na}^{+}$compartmentation in vacuole

- Cell wall modification

- Control of vesicle trafficking

- Production of osmoprotectants

- $\mathrm{K}^{+}$and $\mathrm{NO}_{3}$ homeostasis

- ROS detoxification

- Protein transport

Organ level adaptation

- Leaf

- Salt partitioning into

sheath/petiole or epidermis

- Salt loading in mature

leaves

- Re-translocation of salt or

- Stem

excretion salt bladders

- Control of long-distance

transport

- Salt exclusion in leaf tissues

- Salt storage in stem

- Roots

- Salt exclusion ( 95\%)

- Removal of salt from xylem

- Symbiosis with PGPR

- Changes in root architecture

FIGURE 3 | An overview of adaptive mechanisms of rice species under salinity stress. Diagram shows the main salt tolerance mechanisms such as $\mathrm{Na}^{+}$exclusion in the roots, enhanced xylem $\mathrm{Na}^{+}$unloading, $\mathrm{Na}^{+}$compartmentalization in vacuoles, $\mathrm{Na}^{+}$exclusion in leaf blades/salt glands.

$(S K C 1)$ is responsible for $\mathrm{Na}^{+}$exclusion in the vasculature for protecting leaf blades and reproductive tissues from salt toxicity in rice (Kobayashi et al., 2017). SKC1 is preferentially expressed in parenchyma cells surrounding xylem vessels for efficient recirculation of $\mathrm{Na}^{+}$by unloading $\mathrm{Na}^{+}$into the xylem thereby decreasing $\mathrm{Na}^{+}$accumulation in shoots, contributing to increased salinity tolerance (Ren et al., 2005). Similarly, the rice $\mathrm{K}^{+}$transporter protein, OsHKT1;4, a non-selective transporter, controls the uptake of $\mathrm{Na}^{+}$during the reproductive growth stage (Suzuki et al., 2016), and OsHKT1;1 is associated with the regulation $\mathrm{Na}^{+}$accumulation in shoots where it is mainly expressed in the phloem of leaf blades and is up-regulated in response to salinity stress (Garciadeblás et al., 2003).

The efficient exclusion of $\mathrm{Na}^{+}$excess from the cytoplasm and vacuolar $\mathrm{Na}^{+}$accumulation is the most important step toward the maintenance of ion homeostasis inside the cell. The $\mathrm{Na}^{+} / \mathrm{H}^{+}$ antiporters, SOS1 and NHX1, are the key genes involved in active $\mathrm{Na}^{+}$extrusion to the apoplast and $\mathrm{Na}^{+}$compartmentation in the vacuole, respectively (Figure 3 ). Both antiporters are driven by a proton-motive pump force generated by $\mathrm{H}^{+}$-ATPase (Blumwald, 2000). Overexpression of SOS1 of multiple plant species leads to salt tolerance in plants (Shi et al., 2000; Pardo et al., 2006; Oh et al., 2009; Olías et al., 2009). An OsSOS1 loss of function mutant displayed exceptional salt sensitivity that was correlated with excessive $\mathrm{Na}^{+}$uptake and impaired $\mathrm{Na}^{+}$loading into the xylem (El Mahi et al., 2019). NHXs sequester $\mathrm{Na}^{+}$into vacuoles and are used for osmotic adjustment in salt tolerant plants (Apse et al., 1999; Nieves-Cordones et al., 2016). NHXs mediate $\mathrm{Na}^{+}$ influx in exchange for $\mathrm{H}^{+}$efflux from vacuoles or endosomes that makes them excellent regulators of intracellular $\mathrm{pH}$ (Bassil and Blumwald, 2014; Reguera et al., 2015). In rice, overexpression of OsNHX1 contributes to $\mathrm{Na}^{+}$compartmentalization in old leaves (Wang et al., 2012) and the expression of OsNHX1, OsNHX2, $O s N H X 3$, and OsNHX5 is regulated differently in rice tissues and is increased by salinity stress (Fukuda et al., 2011).

Enhanced xylem $\mathrm{K}^{+}$loading and translocation is another key determinant of salinity tolerance (Assaha et al., 2017). The highaffinity $\mathrm{K}^{+}$transporters, OsHAK1, and OsHAK5, are essential for maintaining $\mathrm{K}^{+}$-mediated growth and development of rice plants under salinity stress. Overexpression of OsHAK1 in rice increased $\mathrm{K}^{+}$uptake, maintaining high $\mathrm{K}^{+} / \mathrm{Na}^{+}$ratio for salt tolerance (Chen et al., 2015a,b). Overexpression of OsHAK5 
increased the $\mathrm{K}^{+} / \mathrm{Na}^{+}$ratio in the shoots, while knockout of OsHAK5 decreased shoot $\mathrm{K}^{+} / \mathrm{Na}^{+}$ratio, resulting in sensitivity to salt stress (Yang et al., 2014). The OsHAK family has many other members that may also have roles in salinity tolerance in rice, which requires further investigation.

Upon exposure to salinity stress, the competitive inhibition of $\mathrm{K}^{+}$uptake by $\mathrm{Na}^{+}$often leads to $\mathrm{Na}^{+}$interfering in many $\mathrm{K}^{+}$-dependent processes ( $\mathrm{Wu}$ et al., 2018). Among the $\mathrm{K}^{+}$channels that have been found in rice that control $\mathrm{K}^{+}$ homeostasis during salinity stress is the inward-rectifying $\mathrm{K}^{+}$ channel, OsAKTs (Fuchs et al., 2004). The maintenance of high $\mathrm{K}^{+}$levels in the cell by preventing of $\mathrm{K}^{+}$efflux is also important for salinity tolerance in plants (Chen et al., 2005). Jayakannan et al. (2013) demonstrated that an influx of $\mathrm{Na}^{+}$in cells depolarizes cell membranes, leading to $\mathrm{K}^{+}$efflux through depolarization-activated $\mathrm{K}^{+}$outward rectifying channels, such as GORK in Arabidopsis. In rice, two outward $\mathrm{K}^{+}$rectifying, shaker-like channels have been identified: OsSKOR (stelar $\mathrm{K}^{+}$ outward rectifier) and OsGORK. OsSKOR is expressed in root vascular tissues, flowers, and the seed scutellum, while OsGORK is expressed to some degree in all tissues (Kim et al., 2015). Liu et al. (2019) showed upregulation of OsGORK and OsAKT1 in tolerant varieties which aids in $\mathrm{K}^{+}$retention in roots when seedlings are exposed to salinity stress. Further elucidation of the roles of this $\mathrm{K}^{+}$channels in salinity stress still needs to be studied.

In plants, there are three primary proton transport proteins: (1) plasma membrane (PM) and (2) vacuolar $\mathrm{H}^{+}$-ATPases, which couple ATP hydrolysis with proton transport, and (3) $\mathrm{PM}$ and vacuolar $\mathrm{H}^{+}$-PPases, which couple pyrophosphate hydrolysis with proton transport (Gaxiola et al., 2007; Fuglsang et al., 2010). Overexpression studies showed that these proton pumps act synergistically together with key ion transporters genes for enhance salinity tolerance. Rice plants overexpressing tonoplast $O s N H X 1$ and $\mathrm{H}^{+}$-pyrophosphatase $(O s V P 1)$ incurred less damage and had higher photosynthetic activities when exposed to long-term salinity (Liu et al., 2010). It was also shown that the salt-tolerant rice (cv. Pokkalli) shows a rapid and significant increase in expression of vacuolar $\mathrm{H}^{+}$ATPases (OsVHA) and OsHKT2 compared to a sensitive line under salinity stress (Kader et al., 2006).

\section{New Mechanisms for Salt Tolerance in Wild Rice}

Despite selective breeding or better $\mathrm{Na}^{+}$exclusion, even salttolerant rice varieties lack tissue tolerance (Yeo and Flowers, 1986; Prusty et al., 2018). This calls for a shift in paradigm in rice breeding for salinity tolerance and the need to target some other (previously underutilized) traits. Such additional mechanisms may include compartmentalization of $\mathrm{Na}^{+}$in roots and older leaves, higher tissue tolerance, efficient ROS production, regulation of stomatal function to control transpiration and passive solute accumulation. Since salinity tolerance is a complex quantitative trait, these mechanisms will not be equally expressed among tolerant cultivated rice. Some salt-tolerant varieties may only contain one or few traits or some may be salt-tolerant at the seedling stage but not at the reproductive stage (Yeo and
Flowers, 1986; Ismail and Horie, 2017). Thus, identification of diverse germplasm with high salinity tolerance and integration of all physiological mechanisms should be a long-term goal for salinity stress enhancement in cultivated rice. However, there is a large knowledge gap due to the paucity of research work on breeding salinity tolerance using wild Oryza species. Here, we summarize the recent progress on the understanding the salt tolerance mechanisms in wild rice (Supplementary Table S2).

Among the wild rice relatives, O. rufipogon, having the same AA genome and the highest compatibility with $O$. sativa (Khush, 1997), is most often used for breeding salinity-tolerant lines. Ganeshan et al. (2016) showed that crosses between O. sativa and O. rufipogon or O. nivara could result in salinity tolerance. Hybrids of $O$. rufipogon $\times O$. sativa were found to contain nine quantitative trait loci $(\mathrm{QTL})$ and candidate genes (e.g., HKT1;5, HAK6 and some transcriptional factors) controlling the salt tolerance at the seedling stage (Quan et al., 2018), and 13 of 15 QTLs for salinity tolerance found were from O. rufipogon (Tian et al., 2011). Wang et al. (2017) identified 10 QTLs for salt tolerance from introgression lines derived from O. rufipogon and O. sativa (cv. 93-11). RNA-sequencing found four differentially expressed genes, OsGH3-2, OsGH38, CML15, and GEM, located in these QTL regions from O. rufipogon. Recombinant inbred lines (RILs) also derived from a cross of $O$. rufipogon $\times O$. sativa showed superior performance with respect to salinity stress (Quan et al., 2018). The cultivated varieties, BRRI Dhan 55(AS996), in Bangladesh and DRR Dhan 40, Jaraya and Chinsurah Nona 2 in India have been released after interspecific hybridization with $O$. rufipogon or O. nivara (Supplementary Table S1). Accessions of Indian wild rice germplasm of $O$. rufipogon and $O$. nivara were screened for their level of salt tolerance. Linkage disequilibrium (LD) analysis showed significant associations of single nucleotide polymorphisms (SNPs) in key genes for the salt tolerant phenotype (Mishra et al., 2016). In addition, overexpression of the bHLH transcription factors, OrbHLHOOI and OrbHLH2, from $O$. rufipogon resulted in salt-tolerant lines of $O$. sativa (Zhou et al., 2009; Li et al., 2010; Chen et al., 2013). OrbHLHOO1 positively regulates the inwardly rectifying $\mathrm{K}^{+}$channel, AKT, which implies that tolerance is due to $\mathrm{K}^{+}$homeostasis under high $\mathrm{Na}^{+}$(Chen et al., 2013). However, O. rufipogon and O. nivara are not halophytes and are unlikely to dramatically improve salt tolerance in cultivated rice in the future, as the lines produced can only survived $8-12 \mathrm{dSm}^{-1}$ (Habiba et al., 2015), which may not be enough if the drastic impact of salinity continues.

Physiological traits for salt tolerance of $O$. officinalis and O. latifolia were compared to the salt-sensitive wild species, $O$. rufipogon and $O$. australiensis. Both $O$. officinalis and O. latifolia accumulate a high content of $\mathrm{Na}^{+}$content in leaves and maintain a constant photosynthetic rate under high salinity (Nishizawa et al., 2015, 2016). These studies showed that there are genes related to photosynthesis associated with salinity tolerance in both O. officinalis and O. latifolia that need to be identified and functionally characterized. The Australian wild rice species, $O$. meridionalis and $O$. australiensis, showed variable tolerance to salinity. Similar to the salt tolerant rice variety, Pokkalli, O. australiensis, had less growth inhibition, lower leaf damage, 
and less biomass reduction (Yichie et al., 2018). Prusty et al. (2018) tested 22 different wild rice species and found that some wild species exhibit superior growth under salinity stress than cultivated rice. O. coarctata was found to be the most tolerant wild species, followed by O. latifolia and O. alta (Prusty et al., 2018). The wild rice species except $O$. coarctata had higher $\mathrm{Na}^{+}$contents in their leaves and low accumulation in roots (Prusty et al., 2018). The potential of the genes conferring salinity tolerance in these wild rice relatives especially in $O$. coarctata remains untapped, and their ability to confer salt tolerance needs further evaluation.

\section{THE HALOPHYTIC WILD RICE SPECIES, Oryza coarctata}

Oryza coarctata, formerly known as Porteresia coarctata, is an allotetraploid wild rice with high salt and submergence tolerance (Lu and Ge, 2003). Oryza coarctata is unique among wild rice species in having the KKLL genome, and phylogenetic analysis suggests that it was one of the basal lineages of rice during grass evolution (Ammiraju et al., 2008). It thrives in coastal areas where it is submerged daily in seawater (Sengupta and Majumder, 2010; Garg et al., 2014). Oryza coarctata has shallow roots and waxy leaves, and it has a highly differentiated rhizome system which serves as a salt depository to give tolerance to the daily intrusion of seawater (Sengupta and Majumder, 2010). Propagation of $O$. coarctata is achieved through nodes of the rhizome where the leaf buds are derived (Sengupta and Majumder, 2009). It has been established as an important resource of genes to improve cultivated rice (Garg et al., 2014).

Unicellular trichomes (salt hairs/salt bladders) on O. coarctata leaves are the most important morphological adaption to salinized environments (Bal and Dutt, 1986; Flowers et al., 1990). The salt hairs present on leaf adaxial are finger-shaped and can continuously secrete salt-forming crystals on leaf surfaces, a mechanism similar to that known for other halophyte grasses (Sengupta and Majumder, 2009, 2010). $\mathrm{Na}^{+}$concentrations in leaves of $O$. coarctata do not increase during salinity stress (Sengupta and Majumder, 2009), and concentrations of sodium ions washing of the leaves of $O$. coarctata are significantly higher compared to other wild rice relatives, suggesting $\mathrm{Na}^{+}$ion extrusion from the leaf surface (Prusty et al., 2018). Therefore, this is an efficient salinity adaptation strategy to maintain low $\mathrm{Na}^{+} / \mathrm{K}^{+}$ratio in the cytosol in the leaf mesophyll while still benefiting from using $\mathrm{Na}^{+}$as a cheap osmoticum.

In addition to its morphological adaptations, many physiological adaptions have been reported for $O$. coarctata including the maintenance of a low $\mathrm{Na}^{+} / \mathrm{K}^{+}$ratio, a high photosynthetic efficiency, maintenance of relative water contents, and efficient functioning of vacuolar $\mathrm{H}^{+}$-ATPase under salinity stress (Senthilkumar et al., 2005). Oryza coarctata plants maintain a $\mathrm{Na}^{+}: \mathrm{K}^{+}$ratio at 0.7 in mesophyll cells, 1.3 in roots and 7.3 in root hairs while the environment's $\mathrm{Na}^{+}: \mathrm{K}^{+}$ratio is 34.0 (Sengupta and Majumder, 2009). Bal and Dutt (1986) reported similar results and estimated that this species is able to exclude around $22 \mathrm{mmol} \mathrm{day}^{-1}$ of $\mathrm{Na}^{+}$per $\mathrm{kg}$ of fresh leaves under a $25 \%$ seawater salinity treatment. Oryza coarctata is similar to most plants in accumulating higher $\mathrm{Na}^{+}$and $\mathrm{K}^{+}$contents in shoots than roots (Bal and Dutt, 1986; Flowers et al., 1990); however, potassium contents barely decrease with increasing salt content (Sengupta and Majumder, 2009). This suggests that O. coarctata might have strong, long-distance $\mathrm{K}^{+}$transport and retention mechanisms. Moreover, calcium may be an important factor in salinity tolerance of $O$. coarctata by preventing sodium influx and $\mathrm{K}^{+}$efflux from NSCC channels as well as by other calcium-activated mechanisms (Sengupta and Majumder, 2010).

Recently, a de novo assembly of the $665 \mathrm{Mb}$ of the O. coarctata genome containing 34,469 predicted protein-encoding genes was first made available by Mondal et al. (2018). Several genes have been sequenced by PCR-based cloning, but only 498 ESTs are available in the NCBI database to date (Chowrasia et al., 2019). The transcription of $O c N H X 1$ was found to be regulated during the day in seawater and was also rapidly induced by salinity treatment to sequester $\mathrm{Na}^{+}$into vacuoles (Kizhakkedath et al., 2015). Some O. coarctata proteins involved in ROS detoxification, photorespiration, cell wall biosynthesis, are highly upregulated under salinity stress in leaves (Sengupta and Majumder, 2009). No systematic study has been conducted to assess salinity stress tolerance in transgenic rice plants expressing genes from O. coarctata; thus, much physiological and molecular research remains to determine to decipher high salinity tolerance in this wild rice. Given the presence of stress-responsive genes and distinct morphological adaptation, O. coarctata should be considered as a rich genetic resource containing many genes that can be used for rice improvement of resistance to salinity stress.

\section{UTILIZING WILD Oryza germplasm FOR BREEDING SALT-TOLERANT RICE VARIETIES}

Crop domestication is thought to be one of the most important events that initiated human civilization. Progressive human selection of genetically inherited traits contributed to higher crop production and better-quality during centuries of domestication (Sengupta and Majumder, 2009). However, important traits responsible for tolerance to biotic and abiotic stress are likely to have been lost during the domestication process. Breeders are refocusing on stress tolerance traits found in wild relatives of crops that remain undisturbed in their natural habitats to facilitate the breeding abiotic and biotic stress tolerant crops (Dai et al., 2014; Wang X. et al., 2018). Most research and breeding efforts toward developing salinity tolerant cultivated rice have focused on tolerance mechanisms at the seedling stage (Ismail et al., 2007). However, due to variation in salinity stress response at rice growth stages, tolerance at both the seedling stage and the reproductive stage are currently being taken into consideration by breeders (Ismail et al., 2007; Hossain et al., 2015).

Salinity tolerance is a polygenic trait that involves a complex of responses at cellular, molecular, physiological and whole plant levels and varies depending on the growth stage. Developing salinity-tolerant rice should encompass all these different attributes. Future breeding strategies should prioritize the identification and introgression of candidate genes/QTLs 
from wild rice species for traits that are not available in cultivated rice. For example, tissue tolerance to salinity is a key trait found in the different wild rice species and consequently molecular markers, RILs, segment substitution lines (CSSL) are being developed for mapping these genes/QTLs for use in breeding and functional genomics. The major goal is to identify several donors contributing to all the traits conferring salinity tolerance and pyramiding them to enhance varietal development.

In rice, over the course of domestication, introgression of wild rice germplasm from cross compatible species such as $O$. rufipogon and $O$. nivara has occurred, and these species still stand out as active sources of germplasm for enhancement of salinity tolerance (Brar and Singh, 2011). Salinity-tolerant varieties have already been developed and released using these two wild rice species (Chen et al., 2004; Song et al., 2005). The other eight wild rice species with AA genomes can be easily hybridized by conventional breeding (Khush, 1997). However, they are comparatively sensitive to salinity in comparison to halophytic O. coarctata that can withstand $40 \mathrm{dSm}^{-1}$ of $\mathrm{NaCl}$. The crossability of Oryza species is related to their phylogenetic relationships (Khush, 1997) (Figure 2), and O. coarctata is not well utilized for breeding because of its genetic distance to
O. sativa. Initial attempts to developed hybrid lines have met limited success (Jena, 1994). Crosses made with O. coarctata and several salt sensitive cultivars such as IR28, IR36, and Tellahasma suffer drawbacks due to pre- and post-fertilization barriers. Through concerted efforts over the years, advanced introgression lines $\left(\mathrm{BC}_{n} \mathrm{~F}_{n}\right)$ derived from IR56 $\times$ O. coarctata that are highly tolerant to salinity stress that can stand $24 \mathrm{dSm}^{-1}$ have been produced at IRRI. A proposed breeding pipeline in producing the salt tolerant varieties using $O$. coarctata is presented in Figure 4. $\mathrm{F}_{1}$ progeny are usually sterile due to various incompatibility barriers, but can be used as female parent in backcrossing attempts to produce advanced backcross (BC) progenies and restore fertility through embryo rescue producing an $\mathrm{BC}_{1} \mathrm{~F}_{1}$. Subsequently, such plants can be cloned vegetatively for the next round of backcrossing. The same technique can be used to produce the $\mathrm{BC}_{2} \mathrm{~F}_{1}$ progenies and so on until advance introgression lines with a high level of salinity tolerance are identified. Individual plants identified as highly tolerant on the rice standard evaluation system (SES) scale (International Rice Research Institute, 2013) can then rescued and subsequently grown for selfing and advancement. Physiological characterization and yield assessment of such

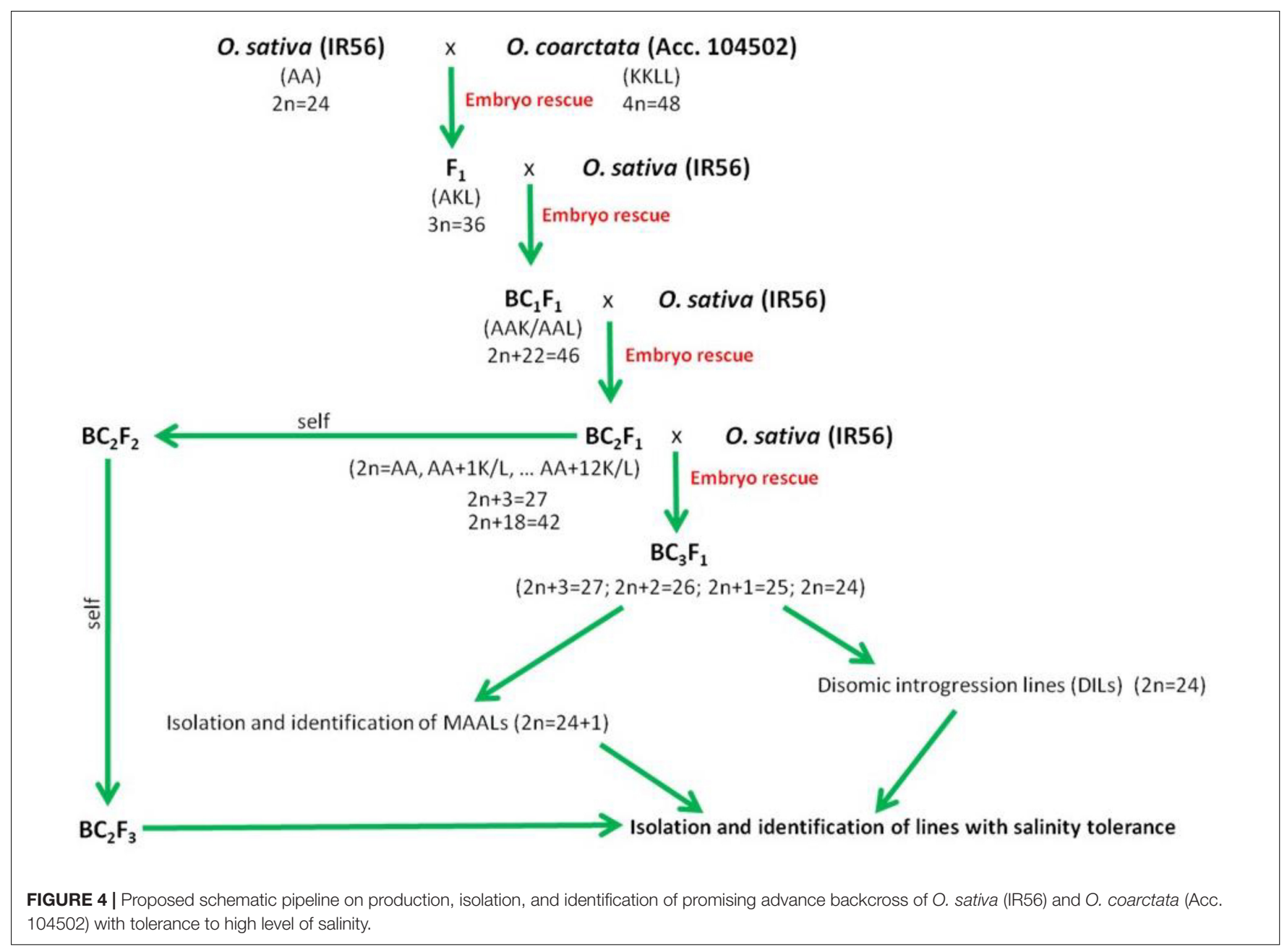


progenies to identify the underlying mechanism of tolerance is on-going. The use of bridge species for transferring salinity tolerance to $O$. coarctata should also be taken into consideration. As genetic analysis using RAPD and AFLP markers revealed that $O$. coarctata is closely related to O. australiensis (Rangan et al., 2002), it is hypothesized that $F_{1}$ hybrids of $O$. coarctata with $O$. australiensis may facilitate breeding using the former species (Latha et al., 2004).

Recent advances in biotechnology, tissue culture, molecular cytogenetics, comparative genomics, and genomics of rice has enabled gene transfer from wild relatives to cultivate rice. Genetic engineering overcomes barriers to conventional breeding and substantially increases the size of the available gene pool for rice improvement (Key et al., 2008). The most used techniques are electroporation, biolistics, and Agrobacterium tumefaciens-mediated transformation and have been used for gene overexpression and silencing in rice (Azhakanandam et al., 2015). The large effort to increase stress tolerance in plants by genetic manipulation has resulted in some significant achievements (Flowers, 2004). In addition, mutation breeding has made a significant contribution toward the production of high yielding and salt stress tolerant rice varieties (Das et al., 2017). Several mutation breeding studies have resulted in rice cultivars with enhanced salinity tolerance, showing many candidate genes related to antioxidants, transcription factors, signaling, ion homeostasis, and transporters to have key roles in salinity tolerance (Hernández, 2019).

The use of wild relatives as a gene pool for new alleles to confer salinity stress tolerance to cultivated species has been successful in other species. For instance, the introgression of the wheat Nax2 locus, which contains the TmHKT1;5-A allele from Triticum monococcum, confers enhanced salt tolerance with reduced $\mathrm{Na}^{+}$ accumulation in leaves. This has resulted in the wide distribution of germplasm expressing Nax2 to wheat growers (James et al., 2011; Mickelbart et al., 2015). Wild tomato relatives such as Lycopersicon cheesmanii have provided sources of salt tolerance for the cultivated tomato Lycopersicon esculentum (Rick and Chetelat, 1995). Considering the different growth environments and habitats for the wild Oryza species, it is expected that they also vary in abiotic stress tolerance (Atwell et al., 2014) and will be a rich source of genes.

\section{CONCLUSION AND FUTURE PERSPECTIVES}

Wild rice relatives show potential for improving salt tolerance in cultivated rice, and this review proposes incorporating these

\section{REFERENCES}

Aggarwal, R. K., Brar, D. S., Huang, N., and Khush, G. S. (1997). Differentiation within CCDD genome species in the genus Oryza as revealed by total genomic hybridization and RFLP analysis. Rice Genet. Newsl. 13, 54-57.

Akimoto, M., Shimamoto, Y., and Morishima, H. (1998). Genetic differentiation in Oryza glumaepatula and its phylogenetic relationships with other AA genome species. Rice Genet. Newsl. 14, 37-39. doi: 10.1038/srep13957 traits from wild species into cultivated rice is a promising approach toward improving salinity tolerance in rice. It appears to us that the strategy of rice breeding for better $\mathrm{Na}^{+}$exclusion from uptake employed for the last few decades has reached a plateau and cannot deliver any further improvement in salinity tolerance traits in this species. While effectively dealing with $\mathrm{Na}^{+}$cytotoxicity, such selective breeding requires plants to rely on de novo synthesis of organic osmolytes for osmotic adjustment. This comes with a high carbon cost (Munns and Gilliham, 2015; Munns et al., 2020) and, hence, massive yield penalties. Thus, we call for a paradigm shift in rice breeding and more efforts toward targeting mechanisms of the tissue tolerance. The possible components may include: (1) efficient internal sequestration of $\mathrm{Na}^{+}$in mesophyll cell vacuoles, with a strong emphasis on control of tonoplast leak channels (Shabala et al., 2019); (2) more efficient control of xylem ion loading to allow rapid osmotic adjustment and turgor maintenance in the shoot (Zarei et al., 2019); (3) efficient cytosolic $\mathrm{K}^{+}$retention in both root and leaf mesophyll cells; and (4) incorporating a possibility of $\mathrm{Na}^{+}$sequestration in external structures such as trichomes (Shabala et al., 2014). This calls for a better utilization of the potential of wild rice where such traits are already present. This also implies developing new screening methods by moving from whole-plant to cell-based phenotyping (Wang H. et al., 2018).

\section{AUTHOR CONTRIBUTIONS}

$\mathrm{Z}$-HC designed the research. CS and MY conducted the experiments. CS, RV, KJ, and Z-HC prepared the figures and tables. CS, Z-HC, SS, and $\mathrm{PH}$ wrote the manuscript with contribution from all authors.

\section{ACKNOWLEDGMENTS}

Z-HC and SS acknowledge the support from Department of Industry, Innovation and Science, Australia-India Strategic Research Funds, the Australian Research Council (ARC), and Horticulture Innovation Australia.

\section{SUPPLEMENTARY MATERIAL}

The Supplementary Material for this article can be found online at: https://www.frontiersin.org/articles/10.3389/fpls.2020.00323/ full\#supplementary-material

Ammiraju, J. S. S., Fan, C., Yu, Y., Song, X., Cranston, K. A., Pontaroli, A. C., et al. (2010). Spatio-temporal patterns of genome evolution in allotetraploid species of the genus Oryza. Plant J. 63, 430-442. doi: 10.1111/j.1365-313X.2010.04251. $\mathrm{x}$

Ammiraju, J. S. S., Lu, F., Sanyal, A., Yu, Y., Song, X., Jiang, N., et al. (2008). Dynamic evolution of Oryza genomes is revealed by comparative genomic analysis of a genus-wide vertical data set. Plant Cell 20, 3191-3209. doi: 10.1105/ tpc. 108.063727 
Anschütz, U., Becker, D., and Shabala, S. (2014). Going beyond nutrition: regulation of potassium homoeostasis as a common denominator of plant adaptive responses to environment. J. Plant Physiol. 171, 670-687. doi: 10.1016/ j.jplph.2014.01.009

Apse, M. P., Aharon, G. S., Snedden, W. A., and Blumwald, E. (1999). Salt tolerance conferred by overexpression of a vacuolar $\mathrm{Na}^{+} / \mathrm{H}^{+}$antiport in Arabidopsis. Science 285, 1256-1258. doi: 10.1126/science.285.5431.1256

Assaha, D. V. M., Ueda, A., Saneoka, H., Al-Yahyai, R., and Yaish, M. W. (2017). The role of $\mathrm{Na}^{+}$and $\mathrm{K}^{+}$transporters in salt stress adaptation in glycophytes. Front. Physiol. 8:5098. doi: 10.3389/fphys.2017.00509

Atwell, B. J., Wang, H., and Scafaro, A. P. (2014). Could abiotic stress tolerance in wild relatives of rice be used to improve Oryza sativa? Plant Sci. 215, 48-58. doi: $10.1016 /$ j.plantsci.2013.10.007

Azhakanandam, K., Silverstone, A., Daniell, H., and Davey, M. R. (eds) (2015). Recent Advancements in Gene Expression and Enabling Technologies in Crop Plants. New York, NY: Springer, doi: 10.1007/978-1-4939-2202-4

Bai, X., Wu, B., and Xing, Y. (2012). Yield-related their applications in rice genetic improvement. J. Integr. Plant Biol. 54, 300-311. doi: 10.1111/j.1744-7909.2012. 01117.x

Bal, A. R., and Dutt, S. K. (1986). Mechanism of salt tolerance in wild rice (Oryza coarctata Roxb). Plant Soil 92, 399-404. doi: 10.1007/BF02372487

Bao, Y., and Ge, S. (2004). Origin and phylogeny of Oryza species with the CD genome based on multiple-gene sequence data. Plant Syst. Evol. 249, 55-66. doi: 10.1007/s00606-004-0173-8

Bartels, D., and Sunkar, R. (2005). Drought and salt tolerance in plants. Crit. Rev. Plant Sci. 24, 23-58. doi: 10.1080/07352680590910410

Bassil, E., and Blumwald, E. (2014). The ins and outs of intracellular ion homeostasis: NHX-type cation $/ \mathrm{H}^{+}$transporters. Curr. Opin. Plant Biol. 22, 1-6. doi: 10.1016/j.pbi.2014.08.002

Blumwald, E. (2000). Sodium transport and salt tolerance in plants. Curr. Opin. Cell Biol. 12, 431-434. doi: 10.1016/s0955-0674(00)00112-5

Brar, D. S., and Khush, G. S. (2018). "Wild relatives of rice: a valuable genetic resource for genomics and breeding research," in Compendium of Plant Genomes: The Wild Oryza Genomes, eds T. K. Mondal and R. J. Henry (Berlin: Springer-Verlag), 1-25. doi: 10.1007/978-3-319-71997-9_1

Brar, D. S., and Singh, K. (2011). "Oryza," in Wild Crop Relatives: Genomic and Breeding Resources, Cereals, ed. C. Kole (Berlin: Springer), 321-365. doi: 10. 1007/978-3-642-20450-0

Chen, G., Feng, H., Hu, Q., Qu, H., Chen, A., Yu, L., et al. (2015a). Improving rice tolerance to potassium deficiency by enhancing OsHAK16p: WOX11controlled root development. Plant Biotechnol. J. 13, 833-848. doi: 10.1111/pbi. 12320

Chen, G., Hu, Q., Luo, L., Yang, T., Zhang, S., Hu, Y., et al. (2015b). Rice potassium transporter OsHAK1 is essential for maintaining potassium-mediated growth and functions in salt tolerance over low and high potassium concentration ranges. Plant Cell Environ. 38, 2747-2765. doi: 10.1111/pce.12585

Chen, L. J., Lee, D. S., Song, Z. P., Suh, H. S., and Lu, B. R. (2004). Gene flow from cultivated rice (Oryza sativa) to its weedy and wild relatives. Ann. Bot. 93, 67-73. doi: 10.1093/aob/mch006

Chen, Y., Li, F., Ma, Y., Chong, K., and Xu, Y. (2013). Overexpression of OrbHLH001, a putative helix-loop-helix transcription factor, causes increased expression of $A K T 1$ and maintains ionic balance under salt stress in rice. J. Plant Physiol. 170, 93-100. doi: 10.1016/j.jplph.2012.08.019

Chen, Z., Cuin, T. A., Zhou, M., Twomey, A., Naidu, B. P., and Shabala, S. (2007a). Compatible solute accumulation and stress-mitigating effects in barley genotypes contrasting in their salt tolerance. J. Exp. Bot. 58, 4245-4255. doi: 10.1093/jxb/erm284

Chen, Z., Newman, I., Zhou, M., Mendham, N., Zhang, G., and Shabala, S. (2005). Screening plants for salt tolerance by measuring $\mathrm{K}^{+}$flux: a case study for barley. Plant Cell Environ. 28, 1230-1246. doi: 10.1111/j.1365-3040.2005.01364.x

Chen, Z., Pottosin, I. I., Cuin, T. A., Fuglsang, A. T., Tester, M., Jha, D., et al. (2007b). Root plasma membrane transporters controlling $\mathrm{K}^{+} / \mathrm{Na}^{+}$homeostasis in salt-stressed barley. Plant Physiol. 145, 1714-1725. doi: 10.1104/pp.107. 110262

Chowrasia, S., Kaur, H., Mujib, A., and Mondal, T. K. (2019). Evaluation of Oryza coarctata candidate reference genes under different abiotic stresses. Biol. Plant. 63, 496-503. doi: 10.32615/bp.2019.054
Cordesse, F., Grellet, F., Reddy, A. S., and Delseny, M. (1992). Genome specificity of rDNA spacer fragments from Oryza sativa L. Theor. Appl. Genet. 83-83, 864-870. doi: 10.1007/BF00226709

Cotsaftis, O., Plett, D., Shirley, N., Tester, M., and Hrmova, M. (2012). A twostaged model of $\mathrm{Na}+$ exclusion in rice explained by $3 \mathrm{~d}$ modeling of HKT transporters and alternative splicing. PLoS One 7:e39865. doi: 10.1371/journal. pone.0039865

Dai, F., Chen, Z. H., Wang, X., Li, Z., Jin, G., Wu, D., et al. (2014). Transcriptome profiling reveals mosaic genomic origins of modern cultivated barley. Proc. Natl. Acad. Sci. U.S.A. 111, 13403-13408. doi: 10.1073/pnas.1414335111

Das, G., Patra, J. K., and Baek, K. H. (2017). Insight into MAS: a molecular tool for development of stress resistant and quality of rice through gene stacking. Front. Plant Sci. 8:985. doi: 10.3389/fpls.2017.00985

Demidchik, V., Davenport, R. J., and Tester, M. (2002). Non-selective cation channels in plants. Annu. Rev. Plant Biol. 53, 67-107. doi: 10.1146/annurev. arplant.53.091901.161540

El Mahi, H., Hormaeche, J. P., De Luca, A., Villalta, I., Espartero, J., Arjona, F. G., et al. (2019). A critical role of sodium flux via the plasma membrane $\mathrm{Na}^{+} / \mathrm{H}^{+}$ exchanger SOS1 in the salt tolerance of rice. Plant Physiol. 180, 1046-1065. doi: $10.1104 /$ pp.19.00324

Eynard, A., Lal, R., and Wiebe, K. (2005). Crop response in salt-affected soils. J. Sustain. Agric. 27, 5-50. doi: 10.1300/J064v27n01_03

Flowers, T. J. (2004). Improving crop salt tolerance. J. Exp. Bot. 55, 307-319. doi: $10.1093 /$ jxb/erh003

Flowers, T. J., Flowers, S. A., Hajibagheri, M. A., and Yeo, A. R. (1990). Salt tolerance in the halophytic wild rice, Porteresia coarctata Tateoka. New Phytol. 114, 675-684. doi: 10.1111/j.1469-8137.1990.tb00439.x

Food and Agriculture Organization (2019). The state of the world's biodiversity for food and agriculture: A call to action? Environ. Policy Law 49, 110-112. doi: 10.3233/EPL- 190136

Fuchs, I., Stölzle, S., Ivashikina, N., and Hedrich, R. (2004). Rice $\mathrm{K}^{+}$uptake channel OsAKT1 is sensitive to salt stress. Planta $221,212-221$. doi: $10.1007 /$ s00425004-1437-9

Fuglsang, A. T., Paez-Valencia, J., and Gaxiola, R. A. (2010). "Plant proton pumps: regulatory circuits involving $\mathrm{H}+$-ATPase and H+-PPase," in Transporters and Pumps in Plant Signalling, eds M. Geisler and K. Venema (Berlin: Springer), 39-64. doi: 10.1007/978-3-642-14369-4

Fukuda, A., Nakamura, A., Hara, N., Toki, S., and Tanaka, Y. (2011). Molecular and functional analyses of rice NHX-type $\mathrm{Na}^{+} / \mathrm{H}^{+}$antiporter genes. Planta 233, 175-188. doi: 10.1007/s00425-010-1289-4

Futakuchi, K., Sié, M., and Saito, K. (2012). Yield potential and physiological and morphological characteristics related to yield performance in Oryza glaberrima Steud. Plant Prod. Sci. 15, 151-163. doi: 10.1626/pps.15.151

Ganeshan, P., Jain, A., Parmar, B., Rao, A. R., Sreenu, K., Mishra, P., et al. (2016). Identification of salt tolerant rice lines among interspecific BILs developed by crossing Oryza sativa $\times$ O. rufipogon and O. sativa $\times$ O. nivara. Aust. J. Crop Sci. 10, 220-228.

Garciadeblás, B., Senn, M. E., Bañuelos, M. A., and Rodríguez-Navarro, A. (2003). Sodium transport and HKT transporters: the rice model. Plant J. 34, 788-801. doi: 10.1046/j.1365-313X.2003.01764.X

Garg, R., Verma, M., Agrawal, S., Shankar, R., Majee, M., and Jain, M. (2014). Deep transcriptome sequencing of wild halophyte rice, Porteresia coarctata, provides novel Insights into the salinity and submergence tolerance factors. DNA Res. 21, 69-84. doi: 10.1093/dnares/dst042

Gaxiola, R. A., Palmgren, M. G., and Schumacher, K. (2007). Plant proton pumps. FEBS Lett. 581, 2204-2214. doi: 10.1016/j.febslet.2007.03.050

Ge, S., Sang, T., Lu, B. R., and Hong, D. Y. (1999). Phylogeny of rice genomes with emphasis on origins of allotetraploid species. Proc. Natl. Acad. Sci. U.S.A. 96, 14400-14405. doi: 10.1073/pnas.96.25.14400

Golldack, D., Quigley, F., Michalowski, C. B., Kamasani, U. R., and Bohnert, H. J. (2003). Salinity stress-tolerant and -sensitive rice (Oryza sativa L.) regulate AKT1-type potassium channel transcripts differently. Plant Mol. Biol. 51, 7181. doi: 10.1023/A:1020763218045

Gregorio, G. B., Senadhira, D., Mendoza, R. D., Manigbas, N. L., Roxas, J. P., and Guerta, C. Q. (2002). Progress in breeding for salinity tolerance and associated abiotic stresses in rice. Field Crop. Res. 76, 91-101. doi: 10.1016/S0378-4290(02) 00031-X 
Gur, A., and Zamir, D. (2004). Unused natural variation can lift yield barriers in plant breeding. PLoS Biol. 2:e245. doi: 10.1371/journal.pbio.0020245

Habiba, U., Abedin, M. A., Hassan, A. W. R., and Shaw, R. (eds) (2015). Food Security and Risk Reduction in Bangladesh. Tokyo: Springer.

Hanin, M., Ebel, C., Ngom, M., Laplaze, L., and Masmoudi, K. (2016). New insights on plant salt tolerance mechanisms and their potential use for breeding. Front. Plant Sci. 7:1787. doi: 10.3389/fpls.2016.01787

Hernández, J. A. (2019). Salinity tolerance in plants: trends and perspectives. Int. J. Mol. Sci. 20:E2408. doi: 10.3390/ijms20102408

Hoang, T. M. L., Tran, T. N., Nguyen, T. K. T., Williams, B., Wurm, P., Bellairs, S., et al. (2016). Improvement of salinity stress tolerance in rice: challenges and opportunities. Agronomy 6:54. doi: 10.3390/agronomy6040054

Hossain, H., Rahman, M. A., Alam, M. S., and Singh, R. K. (2015). Mapping of Quantitative Trait Loci associated with reproductive-stage salt tolerance in rice. J. Agron. Crop Sci. 201, 17-31. doi: 10.1111/jac.12086

Huang, X., Yang, S., Gong, J., Zhao, Q., Feng, Q., Zhan, Q., et al. (2016). Genomic architecture of heterosis for yield traits in rice. Nature 537, 629-633. doi: 10. 1038/nature19760

International Rice Genome Sequencing Project (2005). The map-based sequence of the rice genome. Nature 436, 793-800. doi: 10.1038/nature03895

International Rice Research Institute (2013). Standard Evaluation System (SES) for Rice. Manila: International Rice Research Institute.

Ismail, A. M., Heuer, S., Thomson, M. J., and Wissuwa, M. (2007). Genetic and genomic approaches to develop rice germplasm for problem soils. Plant Mol. Biol. 65, 547-570. doi: 10.1007/s11103-007-9215-2

Ismail, A. M., and Horie, T. (2017). Genomics, physiology, and molecular breeding approaches for improving salt tolerance. Annu. Rev. Plant Biol. 68, 405-434. doi: 10.1146/annurev-arplant-042916-040936

Iwamoto, M., Nagashima, H., Nagamine, T., Higo, H., and Higo, K. (1999). pSINE1-like intron of the CatA catalase homologs and phylogenetic relationships among AA-genome Oryza and related species. Theor. Appl. Genet. 98, 853-861. doi: $10.1007 /$ s001220051144

James, R. A., Blake, C., Byrt, C. S., and Munns, R. (2011). Major genes for $\mathrm{Na}+$ exclusion, Nax1 and Nax2 (wheat HKT1;4 and HKT1;5), decrease Na accumulation in bread wheat leaves under saline and waterlogged conditions. J. Exp. Bot. 62, 2939-2947. doi: 10.1093/jxb/err003

Jayakannan, M., Bose, J., Babourina, O., Rengel, Z., and Shabala, S. (2013). Salicylic acid improves salinity tolerance in Arabidopsis by restoring membrane potential and preventing salt-induced $\mathrm{K}^{+}$loss via a GORK channel. J. Exp. Bot. 64, 2255-2268. doi: 10.1093/jxb/ert085

Jena, K. (1994). Production of intergeneric hybrid between Oryza sativa L. and Porteresia coarctata T. Curr. Sci. 67, 744-746.

Jena, K. K., and Kim, S. M. (2010). Current status of brown planthopper (BPH) resistance and genetics. Rice 3, 161-171. doi: 10.1007/s12284-010-9050-y

Kader, M. A., Seidel, T., Golldack, D., and Lindberg, S. (2006). Expressions of OsHKT1, OsHKT2, and OsVHA are differentially regulated under $\mathrm{NaCl}$ stress in salt-sensitive and salt-tolerant rice (Oryza sativa L.) cultivars. J. Exp. Bot. 57, 4257-4268. doi: 10.1093/jxb/erl199

Kanazawa, A., Akimoto, M., Morishima, H., and Shimamoto, Y. (2000). Interand intra-specific distribution of Stowaway transposable elements in AAgenome species of wild rice. Theor. Appl. Genet. 101, 327-335. doi: 10.1007/ s001220051487

Key, S., Ma, J. K. C., and Drake, P. M. W. (2008). Genetically modified plants and human health. J. R. Soc. Med. 101, 290-298. doi: 10.1258/jrsm.2008.07 0372

Khan, M. S. A., Hamid, A., Salahuddin, A. B. M., Quasem, A., and Karim, M. A. (1997). Effect of sodium chloride on growth, photosynthesis and mineral ions accumulation of different types of rice (Oryza sativa L.). J. Agron. Crop Sci. 179, 149-161. doi: 10.1111/j.1439-037X.1997.tb00511.x

Khatun, S., and Flowers, T. J. (1995). Effects of salinity on seed set in rice. Plant Cell Environ. 18, 61-67. doi: 10.1111/j.1365-3040.1995.tb00 544.x

Khush, G. S. (1997). Origin, dispersal, cultivation and variation of rice. Plant Mol. Biol. 35, 25-34. doi: 10.1007/978-94-011-5794-0_3

Kim, H. Y., Choi, E. H., Min, M. K., Hwang, H., Moon, S. J., Yoon, I., et al. (2015). Differential gene expression of two outward-rectifying shaker-like potassium channels OsSKOR and OsGORK in rice. J. Plant Biol. 58, 230-235. doi: 10.1007/ s12374-015-0070-4
Kizhakkedath, P., Jegadeeson, V., Venkataraman, G., and Parida, A. (2015). A vacuolar antiporter is differentially regulated in leaves and roots of the halophytic wild rice Porteresia coarctata (Roxb.) Tateoka. Mol. Biol. Rep. 42, 1091-1105. doi: 10.1007/s11033-014-3848-4

Kobayashi, N. I., Yamaji, N., Yamamoto, H., Okubo, K., Ueno, H., Costa, A., et al. (2017). OsHKT1;5 mediates $\mathrm{Na}^{+}$exclusion in the vasculature to protect leaf blades and reproductive tissues from salt toxicity in rice. Plant J. 91, 657-670. doi: 10.1111/tpj.13595

Koseki, M., Kitazawa, N., Yonebayashi, S., Maehara, Y., Wang, Z. X., and Minobe, Y. (2010). Identification and fine mapping of a major quantitative trait locus originating from wild rice, controlling cold tolerance at the seedling stage. Mol. Genet. Genomics 284, 45-54. doi: 10.1007/s00438-010-0548-1

Kovach, M. J., Sweeney, M. T., and McCouch, S. R. (2007). New insights into the history of rice domestication. Trends Genet. 23, 578-587. doi: 10.1016/j.tig.2007. 08.012

Kromdijk, J., and Long, S. P. (2016). One crop breeding cycle from starvation? How engineering crop photosynthesis for rising $\mathrm{CO}_{2}$ and temperature could be one important route to alleviation. Proc. R. Soc. B Biol. Sci. 283:20152578. doi: 10.1098/rspb.2015.2578

Kumar, V., Singh, A., Mithra, S. V. A., Krishnamurthy, S. L., Parida, S. K., Jain, S., et al. (2015). Genome-wide association mapping of salinity tolerance in rice (Oryza sativa). DNA Res. 22, 133-145. doi: 10.1093/dnares/dsu046

Latha, R., Salekdeh, G. H., Bennett, J., and Swaminathan, M. S. (2004). Molecular analysis of a stress-induced cDNA encoding the translation initiation factor, eIF1, from the salt-tolerant wild relative of rice, Porteresia coarctata. Funct. Plant Biol. 31, 1035-1042. doi: 10.1071/FP03233

Lee, K. S., Choi, W. Y., Ko, J. C., Kim, T. S., and Gregorio, G. B. (2003). Salinity tolerance of japonica and indica rice (Oryza sativa L.) at the seedling stage. Planta 216, 1043-1046. doi: 10.1007/s00425-002-0958-3

Li, F., Guo, S., Zhao, Y., Chen, D., Chong, K., and Xu, Y. (2010). Overexpression of a homopeptide repeat-containing bHLH protein gene (OrbHLH001) from Dongxiang Wild Rice confers freezing and salt tolerance in transgenic Arabidopsis. Plant Cell Rep. 29, 977-986. doi: 10.1007/s00299-010-0883-Z

Lin, H. X., Zhu, M. Z., Yano, M., Gao, J. P., Liang, Z. W., Su, W. A., et al. (2004). QTLs for $\mathrm{Na}^{+}$and $\mathrm{K}^{+}$uptake of the shoots and roots controlling rice salt tolerance. Theor. Appl. Genet. 108, 253-260. doi: 10.1007/s00122-003-1421-y

Linares, O. F. (2002). African rice (Oryza glaberrima): history and future potential. Proc. Natl. Acad. Sci. U.S.A. 99, 16360-16365. doi: 10.1073/pnas.252604599

Liu, J., Shabala, S., Shabala, L., Zhou, M., Meinke, H., Venkataraman, G., et al. (2019). Tissue-specific regulation of $\mathrm{Na}^{+}$and $\mathrm{K}^{+}$transporters explains genotypic differences in salinity stress tolerance in rice. Front. Plant Sci. 10:1361. doi: 10.3389/fpls.2019.01361

Liu, S., Zheng, L., Xue, Y., Zhang, Q., Wang, L., and Shou, H. (2010). Overexpression of OsVP1 and OsNHX1 increases tolerance to drought and salinity in rice. J. Plant Biol. 53, 444-452. doi: 10.1007/s12374-010-9135-6

$\mathrm{Lu}, \mathrm{B} .-\mathrm{R}$., and Ge, S. (2003). Oryza coarctata: the name that best reflects the relationships of Porteresia coarctata (Poaceae: Oryzeae). Nordic J. Bot. 23, 555-558. doi: 10.1111/j.1756-1051.2003.tb00434.x

Lu, F., Ammiraju, J. S. S., Sanyal, A., Zhang, S., Son, R., Chen, J., et al. (2009). Comparative sequence analysis of MONOCULM1-orthologous regions in 14 Oryza genomes. Proc. Natl. Acad. Sci. U.S.A. 106, 2071-2076. doi: 10.1073/pnas. 0812798106

Lutts, S., Kinet, J. M., and Bouharmont, J. (1996). NaCl-induced senescence in leaves of rice (Oryza sativa L.) cultivars differing in salinity resistance. Ann. Bot. 78, 389-398. doi: 10.1006/anbo.1996.0134

Ma, X., Fu, Y., Zhao, X., Jiang, L., Zhu, Z., Gu, P., et al. (2016). Genomic structure analysis of a set of Oryza nivara introgression lines and identification of yieldassociated QTLs using whole-genome resequencing. Sci. Rep. 6:27425. doi: 10. 1038/srep27425

Maathuis, F. J. M., and Amtmann, A. (1999). $\mathrm{K}^{+}$nutrition and $\mathrm{Na}^{+}$toxicity: the basis of cellular $\mathrm{K}^{+} / \mathrm{Na}^{+}$ratios. Ann. Bot. 84, 123-133. doi: 10.1006/anbo. 1999. 0912

Menguer, P. K., Sperotto, R. A., and Ricachenevsky, F. K. (2017). A walk on the wild side: Oryza species as source for rice abiotic stress tolerance. Genet. Mol. Biol. 40, 238-252. doi: 10.1590/1678-4685-gmb-2016-0093

Mickelbart, M. V., Hasegawa, P. M., and Bailey-Serres, J. (2015). Genetic mechanisms of abiotic stress tolerance that translate to crop yield stability. Nat. Rev. Genet. 16, 237-251. doi: 10.1038/nrg3901 
Mishra, S., Singh, B., Panda, K., Singh, B. P., Singh, N., Misra, P., et al. (2016). Association of SNP haplotypes of HKT family fenes with salt tolerance in Indian wild rice Germplasm. Rice 35, 2295-2308. doi: 10.1007/s00299-016-2035-6

Mondal, T. K., Rawal, H. C., Chowrasia, S., Varshney, D., Panda, A. K., Mazumdar, A., et al. (2018). Draft genome sequence of first monocot-halophytic species Oryza coarctata reveals stress-specific genes. Sci. Rep. 8:13698. doi: 10.1038/ s41598-018-31518-y

Morinaga, T. (1964). "Cytogenetical investigations on Oryza species," in Proceedings of the Symposium on Rice Genetics and Cytogenetics, (Amsterdam: Elsevier), 91-103.

Morishima, H., Sano, Y., and Oka, H. I. (1984). Differentiation of perennial and annual types due to habitat conditions in the wild rice Oryza perennis. Plant Syst. Evol. 144, 119-135. doi: 10.1007/BF00986670

Munns, R., Day, D. A., Fricke, W., Watt, M., Arsova, B., Barkla, B. J., et al. (2020). Energy costs of salt tolerance in crop plants. New Phytol. 221, 25-29. doi: $10.1111 / \mathrm{nph} .15864$

Munns, R., and Gilliham, M. (2015). Salinity tolerance of crops - what is the cost? New Phytol. 208, 668-673. doi: 10.1111/nph.13519

Munns, R., and Tester, M. (2008). Mechanisms of salinity tolerance. Annu. Rev. Plant Biol. 59, 651-681. doi: 10.1146/annurev.arplant.59.032607.092911

Ndjiondjop, M. N., Manneh, B., Cissoko, M., Drame, N. K., Kakai, R. G., Bocco, R., et al. (2010). Drought resistance in an interspecific backcross population of rice (Oryza spp.) derived from the cross WAB56-104 (O. sativa) $\times$ CG14 (O. glaberrima). Plant Sci. 179, 364-373. doi: 10.1016/j.plantsci.2010.06.006

Nieves-Cordones, M., Martínez, V., Benito, B., and Rubio, F. (2016). Comparison between Arabidopsis and rice for main pathways of $\mathrm{K}^{+}$and $\mathrm{Na}^{+}$uptake by roots. Front. Plant Sci. 7:992. doi: 10.3389/fpls.2016.00992

Nishizawa, Y., Nakamura, I., Hossain, M. A., Akamine, H., and Zheng, S. H. (2015). Dry matter production and photosynthetic ability of Oryza officinalis Wall ex Watt under salinity stress condition. Japanese J. Crop Sci. 84, 49-55. doi: $10.1626 /$ jcs.84.49

Nishizawa, Y., Nakamura, I., Tamaki, M., Imura, Y., Hossain, M. A., and Zheng, S. H. (2016). Change in $\mathrm{O} 2$ evolution rate and protein property in the leaf blade of Oryza officinalis wall ex watt in response to salinity. Japanese J. Crop Sci. 85, 411-420. doi: 10.1626/jcs.85.411

Oh, D. H., Leidi, E., Zhang, Q., Hwang, S. M., Li, Y., Quintero, F. J., et al. (2009). Loss of Halophytism by interference with SOS1 expression. Plant Physiol. 151, 210-222. doi: 10.1104/pp.109.137802

Olías, R., Eljakaoui, Z., Li, J., De Morales, P. A., MarÍn-Manzano, M. C., Pardo, J. M., et al. (2009). The plasma membrane $\mathrm{Na}^{+} / \mathrm{H}^{+}$antiporter SOS1 is essential for salt tolerance in tomato and affects the partitioning of $\mathrm{Na}^{+}$between plant organs. Plant Cell Environ. 32, 904-916. doi: 10.1111/j.1365-3040.2009.01971.x

Pardo, J. M., Cubero, B., Leidi, E. O., and Quintero, F. J. (2006). Alkali cation exchangers: roles in cellular homeostasis and stress tolerance. J. Exp. Bot. 57, 1181-1199. doi: 10.1093/jxb/erj114

Piegu, B., Guyot, R., Picault, N., Roulin, A., Saniyal, A., Kim, H., et al. (2006). Doubling genome size without polyploidization: dynamics of retrotransposition-driven genomic expansions in Oryza australiensis, a wild relative of rice. Genome Res. 16, 1262-1269. doi: 10.1101/gr.5290206

Platten, J. D., Egdane, J. A., and Ismail, A. M. (2013). Salinity tolerance, $\mathrm{Na}^{+}$ exclusion and allele mining of HKT1;5 in Oryza sativa and O. glaberrima: many sources, many genes, one mechanism? BMC Plant Biol. 13:32. doi: 10.1186/ 1471-2229-13-32

Plett, D. C., and Møller, I. S. (2010). Na ${ }^{+}$transport in glycophytic plants: What we know and would like to know. Plant Cell Environ. 33, 612-626. doi: 10.1111/j. 1365-3040.2009.02086.x

Prusty, M. R., Kim, S. R., Vinarao, R., Entila, F., Egdane, J., Diaz, M. G. Q., et al. (2018). Newly identified wild rice accessions conferring high salt tolerance might use a tissue tolerance mechanism in leaf. Front. Plant Sci. 9:417. doi: 10.3389/fpls.2018.00417

Purugganan, M. D. (2014). An evolutionary genomic tale of two rice species. Nat. Genet. 46, 931-932. doi: 10.1038/ng.3071

Quan, R., Wang, J., Hui, J., Bai, H., Lyu, X., Zhu, Y., et al. (2018). Improvement of salt tolerance using wild rice genes. Front. Plant Sci. 8:2269. doi: 10.3389/fpls. 2017.02269

Rahman, M. A., Thomson, M. J., Shah-E-Alam, M., De Ocampo, M., Egdane, J., and Ismail, A. M. (2016). Exploring novel genetic sources of salinity tolerance in rice through molecular and physiological characterization. Ann. Bot. 117, 1083-1097. doi: 10.1093/aob/mcw030

Rangan, L., Subramanian, H. M. S., Radha, R., and Swaminathan, M. S. (2002). Genetic relationship of Porteresia coarctata Tateoka using molecular markers. Plant Biosyst. 136, 339-348. doi: 10.1080/11263500212331351239

Reddy, A. M., Francies, R. M., Rasool, S. N., and Reddy, V. R. P. (2014). Breeding for tolerance stress triggered by salinity in rice. Int. J. Appl. Biol. 5, 167-176.

Reddy, I. N. B. L., Kim, B. K., Yoon, I. S., Kim, K. H., and Kwon, T. R. (2017). Salt tolerance in rice: focus on mechanisms and approaches. Rice Sci. 24, 123-144. doi: 10.1016/j.rsci.2016.09.004

Reguera, M., Bassil, E., Tajima, H., Wimmer, M., Chanoca, A., Otegui, M. S., et al. (2015). pH regulation by NHX-type antiporters is required for receptormediated protein trafficking to the vacuole in Arabidopsis. Plant Cell 27, 1200-1217. doi: 10.1105/tpc.114.135699

Ren, Z. H., Gao, J. P., Li, L. G., Cai, X. L., Huang, W., Chao, D. Y., et al. (2005). A rice quantitative trait locus for salt tolerance encodes a sodium transporter. Nat. Genet. 27, 1200-1217. doi: 10.1038/ng1643

Rick, C., and Chetelat, R. (1995). Utilization of related wild species for tomato improvement. Acta Hortic. 412, 21-38. doi: 10.17660/actahortic.1995.412.1

Roy, S. J., Negrão, S., and Tester, M. (2014). Salt resistant crop plants. Curr. Opin. Biotechnol. 26, 115-124. doi: 10.1016/j.copbio.2013.12.004

Sakina, A., Ahmed, I., Shahzad, A., Iqbal, M., and Asif, M. (2016). Genetic cariation for salinity tolerance in Pakistani Rice (Oryza sativa L.) germplasm. J. Agron. Crop Sci. 202, 25-36. doi: 10.1111/jac.12117

Sarao, P. S., Sahi, G. K., Neelam, K., Mangat, G. S., Patra, B. C., and Singh, K. (2016). Donors for resistance to brown planthopper Nilaparvata lugens (Stål) from wild rice species. Rice Sci. 23, 219-224. doi: 10.1016/j.rsci.2016.06.005

Sengupta, S., and Majumder, A. L. (2009). Insight into the salt tolerance factors of a wild halophytic rice, Porteresia coarctata: a physiological and proteomic approach. Planta 229, 911-929. doi: 10.1007/s00425-008-0878-y

Sengupta, S., and Majumder, A. L. (2010). Porteresia coarctata (Roxb.) Tateoka, a wild rice: a potential model for studying salt-stress biology in rice. Plant Cell Environ. 33, 526-542. doi: 10.1111/j.1365-3040.2009.02054.x

Senthilkumar, P., Jithesh, M. N., Parani, M., Rajalakshmi, S., Praseetha, K., and Parida, A. (2005). Salt stress effects on the accumulation of vacuolar $\mathrm{H}^{+}$-ATPase subunit c transcripts in wild rice, Porteresia coarctata (Roxb.) Tateoka. Curr. Sci. 89, 1386-1394.

Shabala, S., Bose, J., and Hedrich, R. (2014). Salt bladders: Do they matter? Trends Plant Sci. 19, 687-691. doi: 10.1016/j.tplants.2014.09.001

Shabala, S., Chen, G., Chen, Z. H., and Pottosin, I. (2019). The energy cost of the tonoplast futile sodium leak. New Phytol. 225, 1105-1110. doi: 10.1111/nph. 15758

Shabala, S., and Pottosin, I. (2014). Regulation of potassium transport in plants under hostile conditions: Implications for abiotic and biotic stress tolerance. Physiol. Plant. 151, 257-279. doi: 10.1111/ppl.12165

Shahbaz, M., and Ashraf, M. (2013). Improving Salinity Tolerance in Cereals. Crit. Rev. Plant Sci. 32, 237-249. doi: 10.1080/07352689.2013.75 8544

Sharma, S., Upadhyaya, H. D., Varshney, R. K., and Gowda, C. L. L. (2013). Prebreeding for diversification of primary gene pool and genetic enhancement of grain legumes. Front. Plant Sci. 4:309. doi: 10.3389/fpls.2013.00309

Shi, H., Ishitani, M., Kim, C., and Zhu, J. K. (2000). The Arabidopsis thaliana salt tolerance gene SOS1 encodes a putative $\mathrm{Na}^{+} / \mathrm{H}^{+}$antiporter. Proc. Natl. Acad. Sci. U.S.A. 97, 6896-6901. doi: 10.1073/pnas.120170197

Singh, A. K., Ansari, M. W., Pareek, A., and Singla-Pareek, S. L. (2008). Raising salinity tolerant rice: recent progress and future perspectives. Physiol. Mol. Biol. Plants 14, 137-154. doi: 10.1007/s12298-008-0013-3

Smajgl, A., Toan, T. Q., Nhan, D. K., Ward, J., Trung, N. H., Tri, L. Q., et al. (2015). Responding to rising sea levels in the Mekong Delta. Nat. Clim. Chang. 5, 167-174. doi: 10.1038/nclimate2469

Song, Z., Li, B., Chen, J., and Lu, B. R. (2005). Genetic diversity and conservation of common wild rice (Oryza rufipogon) in China. Plant Species Biol. 20, 83-92. doi: 10.1111/j.1442-1984.2005.00128.x

Stein, J. C., Yu, Y., Copetti, D., Zwickl, D. J., Zhang, L., Zhang, C., et al. (2018). Genomes of 13 domesticated and wild rice relatives highlight genetic conservation, turnover and innovation across the genus Oryza. Nat. Genet. 50, 285-296. doi: 10.1038/s41588-018-0040-0 
Suzuki, K., Yamaji, N., Costa, A., Okuma, E., Kobayashi, N. I., Kashiwagi, T., et al. (2016). OsHKT1;4-mediated $\mathrm{Na}^{+}$transport in stems contributes to $\mathrm{Na}+$ exclusion from leaf blades of rice at the reproductive growth stage upon salt stress. BMC Plant Biol. 16:22. doi: 10.1186/s12870-016-0709-4

Swamy, B. P. M., Kaladhar, K., Reddy, G. A., Viraktamath, B. C., and Sarla, N. (2014). Mapping and introgression of QTL for yield and related traits in two backcross populations derived from Oryza sativa cv. Swarna and two accessions of O. nivara. J. Genet. 93, 643-654. doi: 10.1007/s12041-014-0420-x

Swamy, B. P. M., and Sarla, N. (2008). Yield-enhancing quantitative trait loci (QTLs) from wild species. Biotechnol. Adv. 26, 106-120. doi: 10.1016/j. biotechadv.2007.09.005

Tester, M., and Davenport, R. (2003). Na+ tolerance and Na+ transport in higher plants. Ann. Bot. 91, 503-527. doi: 10.1093/aob/mcg058

Thomson, M. J., de Ocampo, M., Egdane, J., Rahman, M. A., Sajise, A. G., Adorada, D. L., et al. (2010). Characterizing the Saltol quantitative trait locus for salinity tolerance in rice. Rice 91, 503-527.

Tian, L., Tan, L., Liu, F., Cai, H., and Sun, C. (2011). Identification of quantitative trait loci associated with salt tolerance at seedling stage from Oryza rufipogon. J. Genet. Genomics 38, 593-601. doi: 10.1016/j.jgg.2011.11.005

Varshney, R. K., Nayak, S. N., May, G. D., and Jackson, S. A. (2009). Nextgeneration sequencing technologies and their implications for crop genetics and breeding. Trends Biotechnol. 27, 522-530. doi: 10.1016/j.tibtech.2009.05.006

Vaughan, D. A. (1989). The genus Oryza L. Current Status of Taxonomy. IRRI Research Paper Series 138. Manilla: IRRI.

Vaughan, D. A. (1994). The Wild Relatives of Rice: A Genetic Resources Handbook. Manilla: IRRI.

Vaughan, D. A., Morishima, H., and Kadowaki, K. (2003). Diversity in the Oryza genus. Curr. Opin. Plant Biol. 6, 139-146. doi: 10.1016/s1369-5266(03)00009-8

Wambugu, P. W., Nyamongo, D., Ndjiondjop, M.-N., and Henry, R. J. (2018). "Evolutionary relationships among the Oryza species," in Compendium of Plant Genomes the Wild Oryza Genomes, eds T. Mondal, and R. Henry (Cham: Springer), 41-54. doi: 10.1007/978-3-319-71997-9_3

Wang, H., Shabala, L., Zhou, M., and Shabala, S. (2018). Hydrogen peroxideinduced root $\mathrm{Ca}^{2+}$ and $\mathrm{K}^{+}$fluxes correlate with salt tolerance in cereals: towards the cell-based phenotyping. Int. J. Mol. Sci. 19:E702. doi: 10.3390/ijms190 30702

Wang, H., Zhang, M., Guo, R., Shi, D., Liu, B., Lin, X., et al. (2012). Effects of salt stress on ion balance and nitrogen metabolism of old and young leaves in rice (Oryza sativa L.). BMC Plant Biol. 12:194. doi: 10.1186/1471-2229-12-194

Wang, M., Yu, Y., Haberer, G., Marri, P. R., Fan, C., Goicoechea, J. L., et al. (2014). The genome sequence of African rice (Oryza glaberrima) and evidence for independent domestication. Nat. Genet. 46, 982-988. doi: 10.1038/ng.3044

Wang, S., Cao, M., Ma, X., Chen, W., Zhao, J., Sun, C., et al. (2017). Integrated RNA sequencing and QTL mapping to identify candidate genes from Oryza rufipogon associated with salt tolerance at the seedling stage. Front. Plant Sci. 8:1427. doi: 10.3389/fpls.2017.01427

Wang, X., Chen, Z. H., Yang, C., Zhang, X., Jin, G., Chen, G., et al. (2018). Genomic adaptation to drought in wild barley is driven by edaphic natural selection at the Tabigha Evolution Slope. Proc. Natl. Acad. Sci. U.S.A. 115, 5223-5228. doi: $10.1073 /$ pnas.1721749115

Waziri, A., Kumar, P., and Purty, R. S. (2016). Saltol QTL and their tole in salinity tolerance in rice. Austin J. Biotechnol. Bioeng. 3, 1067-1072.
Wing, R. A., Purugganan, M. D., and Zhang, Q. (2018). The rice genome revolution: from an ancient grain to Green Super Rice. Nat. Rev. Genet. 19, 505-517. doi: 10.1038/s41576-018-0024-Z

Wu, H., Zhang, X., Giraldo, J. P., and Shabala, S. (2018). It is not all about sodium: revealing tissue specificity and signalling roles of potassium in plant responses to salt stress. Plant Soil 431, 1-17. doi: 10.1007/s11104-018-3770-y

Yamaguchi, T., and Blumwald, E. (2005). Developing salt-tolerant crop plants: challenges and opportunities. Trends Plant Sci. 10, 615-620. doi: 10.1016/j. tplants.2005.10.002

Yang, C., Zhang, T., Wang, H., Zhao, N., and Liu, B. (2012). Heritable alteration in salt-tolerance in rice induced by introgression from wild rice (Zizania latifolia). Rice 5:36. doi: 10.1186/1939-8433-5-36

Yang, T., Zhang, S., Hu, Y., Wu, F., Hu, Q., Chen, G., et al. (2014). The role of a potassium transporter OSHAK5 in potassium acquisition and transport from roots to shoots in rice at low potassium supply levels. Plant Physiol. 166, 945-959. doi: 10.1104/pp.114.246520

Yeo, A. R., and Flowers, T. J. (1986). Salinity resistance in rice (Oryza sativa L.) and a pyramiding approach to breeding varieties for saline soils. Aust. J. Plant Physiol. 13:161. doi: 10.1071/PP9860161

Yichie, Y., Brien, C., Berger, B., Roberts, T. H., and Atwell, B. J. (2018). Salinity tolerance in Australian wild Oryza species varies widely and matches that observed in O. sativa. Rice 11, 1-14. doi: 10.1186/s12284-018-0257-7

Zarei, M., Shabala, S., Zeng, F., Chen, X., Zhang, S., Azizi, M., et al. (2019). Comparing kinetics of xylem ion loading and its regulation in halophytes and glycophytes. Plant Cell Physiol. 61, 403-415. doi: 10.1093/pcp/pcz205

Zeng, L., and Shannon, M. C. (2000). Effects of salinity on grain yield and yield components of rice at different seeding densities. Agron. J. 92, 418-423. doi: 10.2134/agronj2000.923418x

Zhang, Q. J., and Gao, L. Z. (2017). Rapid and recent evolution of LTR retrotransposons drives rice genome evolution during the speciation of AA-genome Oryza species. G3 7, 1875-1885. doi: 10.1534/g3.116.03 7572

Zhou, J., Li, F., Wang, J. L., Ma, Y., Chong, K., and Xu, Y. Y. (2009). Basic helixloop-helix transcription factor from wild rice $(\mathrm{OrbHLH} 2)$ improves tolerance to salt- and osmotic stress in Arabidopsis. J. Plant Physiol. 166, 1296-1306. doi: 10.1016/j.jplph.2009.02.007

Zhu, Q., Zheng, X., Luo, J., Gaut, B. S., and Ge, S. (2007). Multilocus analysis of nucleotide variation of Oryza sativa and its wild relatives: severe bottleneck during domestication of rice. Mol. Biol. Evol. 24, 875-888. doi: 10.1093/molbev/ msm005

Conflict of Interest: The authors declare that the research was conducted in the absence of any commercial or financial relationships that could be construed as a potential conflict of interest.

Copyright (c) 2020 Solis, Yong, Vinarao, Jena, Holford, Shabala, Zhou, Shabala and Chen. This is an open-access article distributed under the terms of the Creative Commons Attribution License (CC BY). The use, distribution or reproduction in other forums is permitted, provided the original author(s) and the copyright owner(s) are credited and that the original publication in this journal is cited, in accordance with accepted academic practice. No use, distribution or reproduction is permitted which does not comply with these terms. 